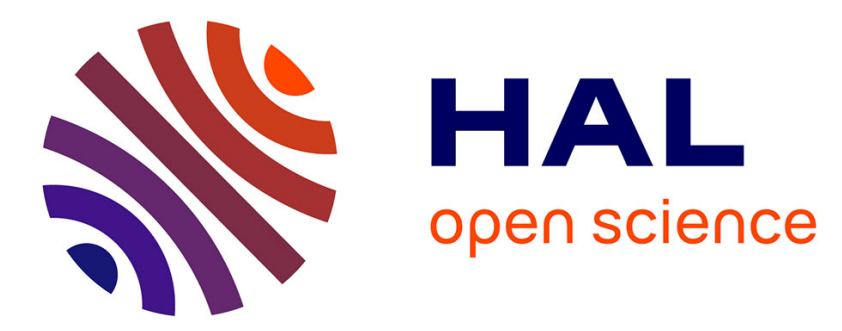

\title{
Progression of excitation-contraction coupling defects in doxorubicin cardiotoxicity
}

Anna Llach, Marianne Mazevet, Philippe Mateo, Olivier Villejoubert, Audrey

Ridoux, Catherine Rucker-Martin, Maxance Ribeiro, Rodolphe Fischmeister, Bertrand Crozatier, Jean-Pierre Benitah, et al.

\section{To cite this version:}

Anna Llach, Marianne Mazevet, Philippe Mateo, Olivier Villejoubert, Audrey Ridoux, et al.. Progression of excitation-contraction coupling defects in doxorubicin cardiotoxicity. Journal of Molecular and Cellular Cardiology, In press, 10.1016/j.yjmcc.2018.11.019 . hal-02463719

\section{HAL Id: hal-02463719 \\ https://hal.science/hal-02463719}

Submitted on 4 Feb 2020

HAL is a multi-disciplinary open access archive for the deposit and dissemination of scientific research documents, whether they are published or not. The documents may come from teaching and research institutions in France or abroad, or from public or private research centers.
L'archive ouverte pluridisciplinaire HAL, est destinée au dépôt et à la diffusion de documents scientifiques de niveau recherche, publiés ou non, émanant des établissements d'enseignement et de recherche français ou étrangers, des laboratoires publics ou privés. 
archives-ouvertes

\title{
Progression of excitation-contraction coupling defects in doxorubicin cardiotoxicity
}

\author{
Olivier Villejoubert, Ana Maria Gómez, Anna Llach, Marianne Mazevet, \\ Philippe Mateo, Olivier Villejouvert, Audrey Ridoux, Catherine \\ Rucker-Martin, Maxance Ribeiro, Rodolphe Fischmeister, et al.
}

\section{To cite this version:}

Olivier Villejoubert, Ana Maria Gómez, Anna Llach, Marianne Mazevet, Philippe Mateo, et al.. Progression of excitation-contraction coupling defects in doxorubicin cardiotoxicity. Journal of Molecular and Cellular Cardiology, Elsevier, In press. hal-02463719

\section{HAL Id: hal-02463719 \\ https://hal.archives-ouvertes.fr/hal-02463719}

Submitted on 4 Feb 2020

HAL is a multi-disciplinary open access archive for the deposit and dissemination of scientific research documents, whether they are published or not. The documents may come from teaching and research institutions in France or abroad, or from public or private research centers.
L'archive ouverte pluridisciplinaire HAL, est destinée au dépôt et à la diffusion de documents scientifiques de niveau recherche, publiés ou non, émanant des établissements d'enseignement et de recherche français ou étrangers, des laboratoires publics ou privés. 


\title{
Progression of excitation-contraction coupling defects in doxorubicin cardiotoxicity
}

\author{
Anna Llach $^{1 *}$, Marianne Mazevet ${ }^{1 *}$, Philippe Mateo ${ }^{1}$, Olivier Villejouvert ${ }^{1}$, Audrey \\ Ridoux ${ }^{1}$, C Rucker-Martin², Maxance Ribeiro ${ }^{1}$, Rodolphe Fischmeister ${ }^{1}$, \\ Bertrand \\ Crozatier $^{1}$, Jean-Pierre Benitah¹, Eric Morel ${ }^{1 \#}$, Ana M Gómez ${ }^{1 \#}$. \\ ${ }^{*}$ Equal contributors
}

${ }^{1}$ UMR-S 1180, "Signaling and cardiovascular pathophysiology", Inserm, Univ. ParisSud,

Université Paris-Saclay, 92296 Châtenay-Malabry, France.

2 UMR-S 999, INSERM, Hôpital Marie Lannelongue, Univ. Paris-Sud, Université Paris-

Saclay, 92350 Le Plessis Robinson, France.

\#Corresponding:

Eric Morel and Ana M Gómez

UMR-S1180, Inserm

Faculté de Pharmacie,

Université Paris Sud

92296 Châtenay-Malabry,

France

e-mail: eric.morel@u-psud.fr

ana-maria.gomez@inserm.fr

MM present address: National Cancer Center-Research Institute. Division of Cellular Signaling. 5-1-1 Tsukiji, Chuo-ku, Tokyo 104-0045, Japan;

AL present address: Regulation of Cardiac Rhythm and Contraction, Research Institute at Santa Creu i Sant Pau Hospital, 08025 Barcelona, Spain. 


\section{Abstract}

Cardiac failure is a common complication in cancer survivors treated with anthracyclines. Here we followed up cardiac function and excitation-contraction (EC) coupling in an in vivo doxorubicin (Dox) treated mice model (iv, total dose of $10 \mathrm{mg} / \mathrm{Kg}$ divided once every three days). Cardiac function was evaluated by echocardiography at 2, 6 and 15 weeks after the last injection. While normal at 2 and 6 weeks, ejection fraction was significantly reduced at 15 weeks. In order to evaluate the underlying mechanisms, we measured $\left[\mathrm{Ca}^{2+}\right]_{\mathrm{i}}$ transients by confocal microscopy and action potentials (AP) by patch-clamp technique in cardiomyocytes isolated at these times. Three phases were observed: 1/ depression and slowing of the $\left[\mathrm{Ca}^{2+}\right]_{\mathrm{i}}$ transients at 2 weeks after treatment, with occurrence of proarrhythmogenic $\mathrm{Ca}^{2+}$ waves, 2/ compensatory state at 6 weeks, and 3/ depression on $\left[\mathrm{Ca}^{2+}\right]_{i}$ transients and cell contraction at 15 weeks, concomitant with invivo defects. These $\left[\mathrm{Ca}^{2+}\right]_{\mathrm{i}}$ transient alterations were observed without cellular hypertrophy or AP prolongation and mirrored the sarcoplasmic reticulum (SR) $\mathrm{Ca}^{2+}$ load variations. At the molecular level, this was associated with a decrease in the sarcoplasmic reticulum $\mathrm{Ca}^{2+}$ ATPase (SERCA2a) expression and enhanced RyR2 phosphorylation at the protein kinase A (PKA, pS2808) site (2 and 15 weeks). RyR2 phosphorylation at the $\mathrm{Ca}^{2+} /$ calmodulin dependent protein kinase II (CaMKII, pS2814) site was enhanced only at 2 weeks, coinciding with the higher incidence of proarrhythmogenic $\mathrm{Ca}^{2+}$ waves. Our study highlighted, for the first time, the progression of Dox treatment-induced alterations in $\mathrm{Ca}^{2+}$ handling and identified key components of the underlying Dox cardiotoxicity. These findings should be helpful to understand the early-, intermediate-, and late- cardiotoxicity already recorded in clinic in order to prevent or treat at the subclinical level. 


\section{Introduction}

Cardiovascular diseases are the main death cause in the world, accounting up to $48 \%$ of non-communicable diseases, followed by cancer at $21 \%$ [1]. Early detection and efficacious management of anticancer therapies have enhanced long term survival rates following cancer. However, cardiovascular complications account for up to $33 \%$ of mortality cause in cancer survivors [2]. Thus cardiotoxicity is a major concern of anticancer therapies [3-6]. On top of the acute side effects, some toxicities manifest later, sometimes years after ending the therapy, hampering the patient quality of life or even their life expectancy. Notably, heart failure (HF) occurs more frequently in patients treated with anthracyclines, whose lead compound is doxorubicin (Dox), compared to any other anticancer therapies, placing anthracyclines as the main cardiotoxic drugs [5]. Different proposed mechanisms such as oxidative stress and cell death have been invoked. Antioxidants have been used in an attempt to prevent cardiotoxic effects, but with poor results or even detrimental effects $[7,8]$. However, $\mathrm{Ca}^{2+}$ homeostasis deregulation could be also of particular importance in the development of Dox-induced cardiotoxicity due to its key role in cardiac functions, such as electrical activity, excitation-contraction (EC) coupling, and excitation-transcription coupling [9]. It is thus important to elucidate the underlying mechanisms of cardiac side effects in order to prevent or limit the cardiotoxic manifestations.

$\mathrm{Ca}^{2+}$ handling has been shown to be altered in HF of other etiologies. Most of the HF models, including human samples, have shown a general depression of the efficacy of the $\mathrm{Ca}^{2+}$-induced $\mathrm{Ca}^{2+}$ release mechanism, characterized by the maintenance of the Ltype $\mathrm{Ca}^{2+}$ current density, and depressed $\left[\mathrm{Ca}^{2+}\right]_{\mathrm{i}}$ transients, together with a prolongation of the action potential (AP) duration [10]. Nevertheless, depressed contractile function in HF of different etiologies may reflect different mechanisms. For instance, while hypertension and myocardial infarction induce the alterations cited above [11-13], 
diabetes-induced cardiac dysfunction [14], and myocardial infarction in the rabbit [15] include a reduction in the L-type $\mathrm{Ca}^{2+}$ current density. Thus, Dox-induced HF may or may not share some alterations with HF of other etiologies.

No much information is known about $\mathrm{Ca}^{2+}$ handling in Dox-induced cardiac dysfunction. Moreover, as HF evolves with time, it is important to get information at different time points, in order to get hints into the progression of Dox cardiotoxicity. While there are some data on acute effects of doxorubicin on EC coupling, very few analyses have addressed the question in Dox -induced cardiac dysfunction after chronic treatment [16]. Isolated cardiac myocytes perfused 30 minutes with Dox [17] showed increased $\mathrm{Ca}^{2+}$ sparks occurrence and decreased $\left[\mathrm{Ca}^{2+}\right]_{i}$ transients. These effects were attenuated, but not completely prevented, by $\mathrm{Ca}^{2+} /$ calmodulin dependent protein kinase II (CaMKII) inactivation. Because $\mathrm{Ca}^{2+}$ sparks reflect ryanodine receptors type 2 (RyR2) openings [18], a direct effect of Dox on the RyR2 may also contribute to the acute effects. In fact, Dox can bind and exert a direct effect on the RyR2 enhancing its activity [19]. As a matter of fact, Dox and its metabolite doxorubicinol directly affects the RyR2, promoting

an initial reversible open probability increase, which might contribute to the elevated $\mathrm{Ca}^{2+}$ sparks rate, following by its inhibition. In addition, recent data have also shown that the anthracycline metabolite doxorubicinol abolishes the RyR2 sensitivity to luminal $\mathrm{Ca}^{2+}$ by interacting with cardiac calsequestrin (CSQ2) favoring arrhythmic conditions [20]. While the Reactive Oxygen Species (ROS) effect might be prevented by antioxidants, the direct effect on RyR2 could not $[21,22]$. Besides these acute effects, some cardiac dysfunctions may appear even years after the end of 4 chemotherapy [7], with progressive 
decrease in the contractile function (measured as ejection fraction) that may lead to irreversible HF [23]. Once clinical signs of HF appeared, the patients are treated as any HF patient with other etiologies, including inhibitors of angiotensin-renin-aldosterone system and $\beta$-blockers $[3,6]$. However, the cellular and molecular mechanisms as well as the progression of the alterations involved in Dox-induced cardiotoxicity are not completely understood.

In the present study, we have performed, for the first time, a complete analysis of the cardiac function by echocardiography in vivo and by $\left[\mathrm{Ca}^{2+}\right]_{i}$ dynamic analysis in cardiomyocytes ex vivo at different times (2, 6 and 15 weeks) after chronic low dose Dox treatment in mice. In parallel, we have investigated the underlying molecular mechanisms. We showed an initial depression in $\left[\mathrm{Ca}^{2+}\right]_{\mathrm{i}}$ transient amplitudes, at 2 weeks after the end of the treatment, that was then compensated at 6 weeks. However, 15 weeks after the end of the treatment, cardiac function was impaired with a reduction of ejection fraction and slight dilation that was correlated with a depression in the $\left[\mathrm{Ca}^{2+}\right]_{\mathrm{i}}$ transients. These 3 phases could be explained at the molecular level by RyR2, SarcoEndoplasmic Reticulum $\mathrm{Ca}^{2+}$ ATPase (SERCA2a) and phospholamban (PLB) alterations. We thus conclude that intracellular $\mathrm{Ca}^{2+}$ alterations precede over cardiac dysfunction in Dox-induced cardiotoxicity without structural alterations (fibrosis and myofibril loss).

\section{Material and Methods}

\subsection{Doxorubicin treated mice}

All experiments were carried out according to the ethical principles laid down by the French and European Union Council Directives for the care of laboratory animals 86/609/ECC. Twelve-week old C57BL/6 male mice received 3 i.v. injections (3 days 
interval) of doxorubicin (Dox) up to a total accumulated dose of $10.1 \pm 0.4 \mathrm{mg} / \mathrm{kg}$. Control animals were injected likewise but with saline solution ( $\mathrm{NaCl} 0.9 \%)$. Data were obtained at 2, 6 and 15 weeks after last i.v. injection. In total we obtained data from 54 mice for saline treatment and 64 for Dox treatment.

\subsection{In vivo recordings}

Transthoracic echocardiography (Vivid 9, General Electric Healthcare, Piscataway, NJ) was performed the day previous cardiomyocyte isolation using a $15 \mathrm{MHz}$ transducer under $3 \%$ isoflurane gas anesthesia. Two-dimensional-guided (2D) M-mode echocardiography was used to determine contractile parameters such as fractional shortening (FS) or ejection fraction (EF), and morphometric parameters.

In vivo telemetric ECG recording was performed in awake free-moving mice, by 7 ETAF10 transmitters (DSI) implants as earlier [24]. ECG analyses were made by EMKA technologies (ECGAUTO).

\subsection{Myocyte isolation}

Ventricular cardiac myocytes were isolated from control and treated mice 2, 6 and 15 weeks after last i.v. injection using a standard enzymatic digestion [25]. Cardiomyocyte morphometric parameters were analyzed by measuring the width, length, and surface area on imageJ pictures obtained from isolated cardiomyocytes. Parameters were determined in a blind manner by computer-assisted planimetry (Perkin Elmer). At least 150 individualized cells per mice and 3-4 animals were analyzed for each condition.

\subsection{Intracellular $\mathrm{Ca}^{2+}$ handling measurement}

Intracellular calcium $\left(\left[\mathrm{Ca}^{2+}\right]_{\mathrm{i}}\right)$ dynamics were recorded in intact ventricular myocytes loaded with fluorescence $\mathrm{Ca}^{2+}$ dye Fluo-3 AM (5 $\mu \mathrm{M}$ for 30 min at RT) with a confocal microscope (see below). To record $\left[\mathrm{Ca}^{2+}\right]_{i}$ transients, cells were electrically stimulated at 
$2 \mathrm{~Hz}$ by field stimulation using two parallel platinum electrodes [25] while perfused with normal Tyrode solution (in $\mathrm{mM}$ ): $\mathrm{NaCl} 140, \mathrm{KCl} 4$, $\mathrm{HEPES} \mathrm{10,} \mathrm{MgCl}_{2}$ 1.1, $\mathrm{CaCl}_{2}$ 1.8, glucose 10; $\mathrm{pH}=7.4$ with $\mathrm{NaOH}$. Spontaneous $\mathrm{Ca}^{2+}$ sparks and waves were obtained in quiescent cells after field-stimulation recordings. In order to estimate Sarcoplasmic Reticulum (SR) $\mathrm{Ca}^{2+}$ content, cells were rapidly exposed to $10 \mathrm{mM}$ caffeine just after field-stimulated at $2 \mathrm{~Hz}$ to allow for stable SR $\mathrm{Ca}^{2+}$ load.

Images were obtained with a laser scanning confocal microscope (TCS SP5X Leica Microsystems) equipped with an x40/x63 water-immersion objective (N.A. 1.4-1.2) in the line scan mode $(1.43 \mathrm{~ms} / \mathrm{line})$. The scanning line was selected parallel to the longitudinal cell axis to be able to measure cell shortening. Fluo-3 was excited with a White light laser tuned at $500 \mathrm{~nm}$, and emission measured at wavelengths above $510 \mathrm{~nm}$. Image analyses were performed by homemade routines running in IDL 8.2 software (Exelis Visual Information Solutions, Inc.). Images were corrected for the background of fluorescence.

\subsection{Immunoblotting}

Mice left ventricles were lysed with RIPA lysis buffer containing protease and phosphatase inhibitors (Roche). Immunodetection by Western-blot was performed by electrophoresis of proteins $(20 \mu \mathrm{g})$ in a $10 \%, 15 \%$ or $4-12 \%$ SDS-PAGE gel, followed by transfer to a PVDF membrane (GE Healthcare). Membranes were blocked with TBSTween $0.1 \%$ - Milk 5\% and incubated with primary antibodies for SERCA2a (Santa Cruz; 1:1000), PLB (Santa Cruz; 1:500), phosphorylated PLB at Ser16 and Thr17 (Badrilla; 1:2000), RyR2 (Pierce, 1:2000), phosphorylated RyR2 at Ser2814 and 2808 (Badrilla; 1:2000) and NCX (Swant; 1:1000). Membranes were incubated with corresponding HRP secondary conjugated antibody (Santa Cruz; diluted at $1: 10000$ in TBST containing 5\% 
milk). Reactive proteins were visualized by chemiluminescence detection system (ChemiDoc ${ }^{\mathrm{TM}}$ MP imaging system, Biorad). Incubation with $\beta$-actin antibody (Santa Cruz Biotechnology, diluted at 1:30000) was performed to normalize the chemiluminescence levels and exposure times. The same pool of protein standards was added to the different WB in order to compare protein quantification along the 15 weeks of experimentations.

\subsection{Histological assessments}

Hearts were fixed in $4 \%$ paraformaldehyde, embedded in paraffin and serial sectioned $(3 \mu \mathrm{m})$. Sections were stained with Picrosirius Red F3BA for interstitial collagen evaluation, or hematoxylin and eosine for global morphology and tissue inflammatory status.

Two to three sections per animal were examined at 20X and 40X magnification, 5-10 fields per section were recorded with an AxioCam MRc camera (Carl Zeiss); analyses were realized with ImageJ software and conducted by two independent investigators. Collagen quantification was expressed as a percentage of total tissue.

\subsection{Statistics}

Experimental data are expressed as means \pm S.E.M. Differences between groups at each time point have been analyzed by one-way ANOVA followed and unpaired Student's $t$-test. Differences were considered statically significant when ${ }^{*} p<0.05$, ${ }^{* *} p<0.01,{ }^{* *} p<0.001$.

\section{Results}




\subsection{Depressed Cardiac Function 15 weeks after last Dox injection}

We aimed to investigate whether Dox influences cardiac function after in vivo treatment. Age and weight matched male mice received 3 iv injections on alternate days up to a cumulative dose of $10 \mathrm{mg}$ Dox. Functional characterization by $\mathrm{M}$ mode echocardiography was performed at 2, 6 and 15 weeks after the last injection. While cardiac function was normal at 2 and 6 weeks, it was significantly depressed 15 weeks after the last injection (Fig. 1A). Namely, the Ejection Fraction (Fig. 1B) and Fractional Shortening (Fig. 1C) were significantly depressed in Dox-treated animals, without alteration of the heart rate measured during echocardiography $(573 \pm 40 \mathrm{bpm}$ in 5 Saline mice vs. $542 \pm 36$ in 7 Dox-treated animals). Dox treatment produced a delay in weight gain during the first two weeks (Supplementary. Fig.S1A) but failed to induce cardiac hypertrophy as indicated by the ratio heart weight to tibia lengths (Supplementary Fig. S1B). Echocardiographic analyses showed slight dilation at 15 weeks after the last injection manifested by a significant increase in the End Diastolic Diameter (Fig. 1D). Lack of development of cardiac hypertrophy was evidenced at the cellular level by the absence of alteration of membrane capacitance (in pF: at 2 weeks $162.4 \pm 20.6 n=10$ Saline vs $157.9 \pm 12.5 n=10$ Dox; at 6 weeks $179.5 \pm 13.9 n=19$ Saline vs $175.2 \pm 17.2 n=19$ Dox; at 15 weeks $171.6 \pm 12.8 n=15$ Saline, vs $218.5 \pm 22.4 n=5$ Dox) or surface area (in $\mu \mathrm{m}^{2}$ : at 2 weeks $3125.9 \pm 191.7$ Saline vs. $3096.0 \pm 238.2$ Dox; at 6 weeks $3009.5 \pm 211.8$

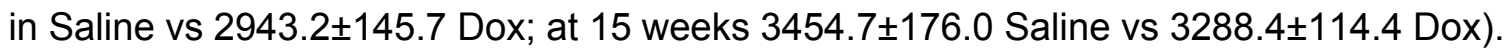
The decrease in contractile function at 15 weeks post treatment could be due to development of fibrosis, or to a defect on the cardiomyocyte contraction itself. We previously showed that cardiac fibrosis was involved in heart dysfunction after radiotherapy [26]. Thus we wanted to investigate whether this mechanism was also present after Dox treatment. No significant fibrosis (Figure 1E) or other structural alteration such as myofibrillar disorganization, or vacuolization (Supplemental Figure 
S1C) in Dox treated animals were observed. These data suggests that the depressed contractile function may be dependent on impaired cardiomyocyte function.

\subsection{Dox treatment Differently Modulated $\left[\mathrm{Ca}^{2+}\right]_{i}$ transients over time}

Since $\mathrm{Ca}^{2+}$ activates cell contraction, depressed contractile function at 15 weeks after Dox treatment, might be due to alterations of intracellular $\mathrm{Ca}^{2+}$ fluxes at cellular level. Figure 2A shows representative examples of line scan images taken from ventricular cardiac myocytes under field-stimulation at $2 \mathrm{~Hz}$. Dox treatment had different effect over time after last i.v. injection, as summarized in Figure $2 \mathrm{~B}$ and $2 \mathrm{C}$ for $\left[\mathrm{Ca}^{2+}\right]_{i}$ transients amplitude $\left(\mathrm{F} / \mathrm{F}_{0}\right)$ and constant of transient decay (Tau), respectively. Since we noticed a variation with age, each data in Dox-treated animals were normalized by the data in Saline-treated animals, thus matching age and time after last injection. $\left[\mathrm{Ca}^{2+}\right]_{i}$ transient amplitude (peak $F / F_{0}$ ) was depressed at 2 weeks after Dox treatment (Figure 2B). However, this initial depression was overcome at 6 weeks, where there was even an increase in the $\left[\mathrm{Ca}^{2+}\right]_{i}$ transient amplitude. Over time and, consistent with the depressed cardiac function observed at 15 weeks after Dox treatment in vivo, we observed a significant decrease in the $\left[\mathrm{Ca}^{2+}\right]_{i}$ transient amplitude (Figure 2B) and slowing of its decay time (Fig. 2C). Unloaded cell shortening was significantly depressed only at 15 weeks after last Dox injection (Fig. 2D). These data suggests that the depression in cardiac contraction 15 weeks after the last Dox injection, is at least in part, due to a depression in the $\left[\mathrm{Ca}^{2+}\right]_{\mathrm{i}}$ transient amplitude.

\subsection{Dox treatment did not alter Action Potential Duration}

As $\left[\mathrm{Ca}^{2+}\right]_{i}$ transients are triggered by action potentials, the differences on $\left[\mathrm{Ca}^{2+}\right]_{\mathrm{i}}$ transients might result from action potential (AP) alterations. As summarized and exemplified in the inset of Figure 3, no alterations were observed in AP duration at 20 
(APD20\%), 50 (APD50\%) nor 90\% repolarization (APD90\%). Other AP parameters were neither affected by Dox-treatment, such as zero current potential nor AP amplitude (data not shown). These cellular data were consistent with no alteration of the QTc measured by telemetry in mice (in ms: $59.3 \pm 1.4[n=7]$ in Saline vs $60.0 \pm 1.8$ in [n=6] Dox-treated mice at $2 \mathrm{~W}$ and $68.0 \pm 2.0[\mathrm{n}=7]$ in saline vs $64.4 \pm 2.5$ in $[\mathrm{n}=5]$ Dox treated mice at 6 weeks).

\subsection{SR Ca ${ }^{2+}$ Load Reduced 15 weeks after last Dox injection}

Since the (AP), which activates the trigger $\left(I_{C a}\right)$ is not altered, modifications in the $\left[\mathrm{Ca}^{2}\right.$ $\left.{ }^{+}\right]_{i}$ transient after Dox treatment might result from differences in the amount of $\mathrm{Ca}^{2+}$ stored in the SR. The SR Ca ${ }^{2+}$ load was estimated by caffeine-evoked $\left[\mathrm{Ca}^{2+}\right]_{\mathrm{i}}$ transients. Cells were field-stimulated at $2 \mathrm{~Hz}$ allowing to achieve stable $\mathrm{SR} \mathrm{Ca}^{2+}$ load, and then were rapidly exposed to $10 \mathrm{mM}$ caffeine as exemplified with the line scan images in Figure 4A, after different times of last injection either with Saline (top) or Dox (bottom). The pattern of amplitudes of the caffeine-evoked $\left[\mathrm{Ca}^{2+}\right]_{\mathrm{i}}$ transients at different times after the last Dox injection (Fig. 4B) paralleled the alterations in $\left[\mathrm{Ca}^{2+}\right]_{i}$ transients amplitudes, namely it was depressed at 15 weeks post Dox injection after a period of increase at 6 weeks. Thus alterations in the $\mathrm{SR} \mathrm{Ca}^{2+}$ load could account for the decrease in the $\left[\mathrm{Ca}^{2+}\right]_{i}$ transients and contractions. Altered expression or function of the proteins involved in $\mathrm{Ca}^{2+}$ release, uptake and/or extrusion such as SERCA2a, PLB, RyR2, and NCX might underlie the decreased SR $\mathrm{Ca}^{2+}$ load at 15 weeks. The decay phase of the electrically evoked $\left[\mathrm{Ca}^{2+}\right]_{i}$ transient in the mouse is mainly due to $\mathrm{Ca}^{2+}$ uptake into the SR by SERCA2a, and in a minor extension to extrusion through the NCX. Other slow systems account for about $1 \%$ [27]. As shown in Fig. $2 \mathrm{C}$, the $\left[\mathrm{Ca}^{2+}\right]_{\mathrm{i}}$ transient decay phase was slowed at 2 and 15 weeks after last Dox injection, suggesting that SERCA2a and/or NCX function or expression are 
depressed at these time points. During caffeine application, the RyR2 are kept open, thus any $\mathrm{Ca}^{2+}$ pumped back by SERCA2a is immediately released through the open RyR2. Consequently the decay phase of the caffeine-evoked $\left[\mathrm{Ca}^{2+}\right]_{i}$ transient is mainly due to extrusion through NCX. No statistically significant difference at any time point after Dox treatment was observed either in the decay time constant of caffeine-evoked transients (Tau, Fig. 4C) or levels of NCX protein expression (Fig. 4D), suggesting that NCX function/expression is not significantly altered after Dox treatment.

We then addressed the SERCA2a expression in our Dox mice model. As shown in western blots examples (Fig. 5A) and averaged data of each animal group (Fig. 5B) and consistent with the $\left[\mathrm{Ca}^{2+}\right]_{i}$ transient decay slowing down (Fig. 2B), significant decreases in SERCA2a expression at 2 and 15 weeks were observed after Dox treatment, compared to the saline treated animals. In addition and showed in Figure $5 \mathrm{C}$ through $\mathrm{F}$, we observed that the total phospholamban levels were normal at 2 and 15 weeks, but reduced at 6 weeks after Dox treatment compared to Saline treated mice (Fig. 5D), without significant alteration of its phosphorylation at Ser16 (Fig. 5E) and at Thr17 (Fig. $5 \mathrm{~F})$ at any analyzed time point following Dox treatment. This might be involved in the compensatory phase observed at 6 weeks.

\subsection{Spontaneous $\mathrm{Ca}^{2+}$ release in Dox-treated mice}

In other models of $\mathrm{HF}$, an increase in the diastolic $\mathrm{Ca}^{2+}$ leak explained by a high activity of RyRs has been invoked to account for reduced SR $\mathrm{Ca}^{2+}$ load. Analysis of the spontaneous $\mathrm{Ca}^{2+}$ sparks in quiescent cells, as exemplified in Figure $6 \mathrm{~A}$, shows an increase in $\mathrm{Ca}^{2+}$ sparks frequency at 2 and 15 weeks (Fig. 6B), coinciding with the time points of depressed $\left[\mathrm{Ca}^{2+}\right]_{\mathrm{i}}$ transients and $\mathrm{SR} \mathrm{Ca}^{2+}$ load. Western blots analyses showed that the level of RyR2 expression was transitorily depressed at 2 weeks after the last injection and normalized afterwards (Fig. 6C \& D). This depression in RyR2 expression 
could account to the initial decrease in the $\mathrm{Ca}^{2+}$ spark amplitude (Supplementary Fig. $\mathrm{S} 2 \mathrm{~A})$. Other $\mathrm{Ca}^{2+}$ sparks characteristics were also differently regulated depending on the time after the last injection. Supplementary Fig. S2 B shows prolonged $\mathrm{Ca}^{2+}$ spark duration at 2 and 15 weeks, time at which SERCA2a level was depressed, and increase in width only at 15 weeks post Dox injection (Supplementary Fig. S2 C). RyR2 phosphorylation level at the PKA site (S2808) was enhanced at 2 and 15 weeks (Fig. $6 \mathrm{C}, \mathrm{E})$, coinciding with the periods of higher $\mathrm{Ca}^{2+}$ sparks frequency. Interestingly, RyR2 phosphorylation at the S2814 site, which is identified as the CaMKII site, was enhanced only early after Dox treatment, at 2 weeks (Fig. 6C \& F). In addition and in accordance with some reports showing that RyR2 phosphorylation at this site was proarrhythmogenic [28], spontaneous $\mathrm{Ca}^{2+}$ waves were enhanced at 2 weeks post treatment (Fig. 6G).

\section{Discussion}

In summary, follow up of the anthracycline-induced cardiotoxicty in mice demonstrated a time dependent alteration in cardiac $\mathrm{Ca}^{2+}$ handling, which culminated to depressed cardiac function 15 weeks after the treatment without electrical, nor hypertrophic cardiomyocyte remodeling, nor myocardial fibrosis. We found that Dox treatment induced an initial increase in diastolic $\mathrm{Ca}^{2+}$ leak, which returned later to normal. However, 15 weeks after the treatment, the animals presented decreased ejection fraction. The latter can be at least in part explained by a depression in the $\left[\mathrm{Ca}^{2+}\right]_{i}$ transients due to reduction in SERCA expression. This Dox-induced calcium handling dysfunction occurred, as opposed to other heart failure models without hypertrophy development nor AP duration alteration. 
We have established a model of in-vivo Dox treatment by 3 i.v. Dox injections within therapeutic levels and without induction of animal death. A fractionated I.V. protocol with a total cumulated dose away from toxic values was chosen in an attempt to be closer to the clinical situation. Similar fractioning and cumulated doses has recently been published by other authors [29]. Echocardiographic data showed a significant depression in the ejection fraction and fractional shortening in Dox-treated mice compared to saline, only 15 weeks after the end of treatment. At that time, the cardiac myocytes unloaded contraction was reduced, and $\left[\mathrm{Ca}^{2+}\right]_{\mathrm{i}}$ transients were significantly depressed and slowed. Although these alterations have been found in models of HF, these alterations appeared in the absence of cardiac remodeling, as neither the heart nor the myocytes were hypertrophied. Moreover, no significant fibrosis was detected. This is in contrast to our previous findings in radiotherapy-induced cardiac dysfunction, where depressed contractile heart function was associated with cardiac fibrosis whereas cellular $\left[\mathrm{Ca}^{2+}\right]_{\mathrm{i}}$ transients were preserved [26]. The lack of fibrosis in our Dox model indicates that at the doses we used, the cardiac dysfunction is not dependent on myocytes cell death and structural alterations in a type I cardiotoxicity manner. This is also in agreement with the clinical observation of a partial or full heart function recovery for a large percentage of patients under Enalapril and $\beta$-blockers treatment $(11 \%$ and $71 \%$ of patients with full or partial recovery respectively) [6]; a phenomenon that would not have been possible if decreased cardiac function would only rely on cell death.

Our results show that $\mathrm{Ca}^{2+}$ handling alteration is already evident 2 weeks after the last Dox injection, but was followed by a compensation phase, at 6 weeks, where neither the cardiac function, nor the $\left[\mathrm{Ca}^{2+}\right]_{\mathrm{i}}$ handling was impaired. The $\left[\mathrm{Ca}^{2+}\right]_{\mathrm{i}}$ transient was thus reduced in amplitude at 2 and 15 weeks post-treatment (Fig. 2), which may reflect the depression on SR $\mathrm{Ca}^{2+}$ content (Fig. 4). Strikingly, even if the $\left[\mathrm{Ca}^{2+}\right]_{\mathrm{i}}$ transient was 
reduced at two weeks, this was not translated into a significant decrease of the unloaded cell contraction, nor the echocardiographic functional parameters. This data suggests thus that Dox treatment could increase myofibrils $\mathrm{Ca}^{2+}$ sensitivity at early stage. This hypothesis is supported by the finding that Dox has a positive inotropic effect by directly acting on contractile myofibrils [30]. While the increased $\mathrm{Ca}^{2+}$ leak through enhanced $\mathrm{Ca}^{2+}$ sparks occurrence (Fig. 6) may be involved in the decreased $\mathrm{SR} \mathrm{Ca}^{2+}$ load, the depression in SR content can be related to the reduced SERCA expression at 2 and 15 weeks after the end of treatment (Fig. 5). In fact, reduction of SERCA function can be observed as the slowing of the $\left[\mathrm{Ca}^{2+}\right]_{i}$ transient at these time points. This result is consistent with the slowing of the $\left[\mathrm{Ca}^{2+}\right]_{i}$ transient in a rat model [31], which however showed alteration of the peak $\left[\mathrm{Ca}^{2+}\right]_{i}$ transient. In addition to the different doses and animal model used, the evolution of the disease may also account for the different effects on $\left[\mathrm{Ca}^{2+}\right]_{i}$ transient amplitude. Interestingly, during the compensatory phase (6 weeks), the PLB level was depressed (Fig. 5). Inhibitory effect of PLB over SERCA function is decreased, resulting in accelerated SR reloading (Fig. 4) and higher peak $\left[\mathrm{Ca}^{2+}\right]_{i}$ transient (Fig. 2) at this time point. Our results echoed biochemical analyses during Dox treatment showing a decrease in both SERCA and PLB cardiac levels at 8 weeks [31-33]. However, SERCA may not be a target to limit cardiotoxic actions of Dox, since SERCA overexpressing mice have lower survival than WT after Dox treatment [34], suggesting that the initial SERCA depression may be a compensatory response.

At 2 and 15 weeks after the last injection, isolated cardiomyocytes showed an increased $\mathrm{Ca}^{2+}$ spark frequency (Fig. 6). This echoes the effect of short incubation of cardiac myocytes in the presence of Dox [17], but contrast with the reported depressed expression of RyR2 in a rabbit in vivo Dox treatment $[33,35]$. At 2 weeks we denoted a decrease in RyR2 expression (Fig. 6) and in $\mathrm{Ca}^{2+}$ spark amplitude (supp. Fig. S2), which 
was normalized later on. However, even at this time point, $\mathrm{Ca}^{2+}$ sparks were more frequent after Dox treatment (Fig. 6B). It has been shown that Dox directly affects RyR2 activity by a rapid reversible activation of the channel and latter causes an irreversible inhibition [21, 22]. In our experimental model, Dox was administered in vivo and experiments were made several weeks after the end of the treatment. The direct effects would thus not be present anymore, as Dox pharmacokinetics after i.v. injection in mice are very fast and almost no present 24 hours after the injection [36]. The enhanced $\mathrm{Ca}^{2+}$ sparks frequency at 2 weeks could be accounted by different phosphorylation level of the RyR2 [17]. In fact, the relative RyR2 phosphorylation level was increased in both PKA and CaMKII sites at 2 weeks and only at the PKA site at 15 weeks after the treatment, coinciding with times of high $\mathrm{Ca}^{2+}$ sparks frequency (Fig. 6). An open question may be what is activating both PKA and CaMKII. Circulating catecholamines are often increased in order to compensate for an insult. This could lead to PKA activation and RyR2 phosphorylation. We can hypothesize, that close to the injections, in an attempt to increase the fight response, the heart is under adrenergic stimulation. Alternatively or additionally, activation of CaMKII and PKA could be related to the oxidant properties of Dox, which has been also shown to be able to activate both kinases [37, 38]. Interestingly we observed only an increase in RyR2 phosphorylation at the CaMKII site at 2 weeks, where proarrhythmogenic $\mathrm{Ca}^{2+}$ waves were more frequent (Fig. 6G). This may reflect the acute arrhythmic phase of anticancer therapy [39]. However, in our in vivo ECG telemetry analyses, we only found one Dox treated mice with ventricular extrasystole at 2 weeks after the last injection and none on saline treated mice. This may be due to the high resistance to arrhythmia of mice. In vitro, [17] upon acute Dox treatment, CaMKII activation and RyR2 phosphorylation have been reported. We found that the RyR2 phosphorylation at the CaMKII site (S2814) is maintained for at least 2 weeks after the treatment. CaMKII activation at earlier point could be due to oxidation 
[37], as Dox activate ROS [16] or by $\mathrm{Ca}^{2+}$ itself, as Dox directly activates RyR2 [19]. This increase in RyR2 phosphorylation at the CaMKII site is transient: at 6 weeks is not significant anymore and completely normal at 15 weeks. Thus at 6 weeks, the normalization of RyR2 expression and phosphorylation levels, together with reduced PLB expression, can underlie this compensatory state. Nevertheless, this compensation has its limits, as at 15 weeks there is a further decrease in SERCA expression and enhanced of the RyR2 phosphorylation at the PKA site.

In summary, we found that mice treated with Dox at therapeutic like doses, significantly induce a clear cardiotoxic effect 15 weeks after treatment. Heart dysfunction at 15 weeks post- treatment may be due, at least in part, to a depressed $\left[\mathrm{Ca}^{2+}\right]_{i}$ transient. The latter may be the reflect of a low SR $\mathrm{Ca}^{2+}$ load due to depression in SERCA expression and enhanced $\mathrm{Ca}^{2+}$ leak through RyRs, which appear early in absence of clear cardiac function alterations, before to be transiently compensated. Our work points out that $\mathrm{Ca}^{2+}$ homeostasis alterations contribute to Dox induced cardiomyopathy, in addition to the classical and current dogma linking cardiotoxicity to the sole cell death. Moreover, this cardiac dysfunction seems to be specific to Dox-induced toxicity, being different from cardiac dysfunction from other etiologies, notably by the lack of hypertrophy and AP alterations.

\section{Sources of funding}

This study was supported by, LabEx LERMIT (ANR-10-LABX-33) and THORINO to EM; CORDDIM (Equipment 2010 and 2012) and ANR-13-BSV1-0023-01 to AMG; and ANR15-CE14-0005 to JPB. AL and MM were recipients of Lefoulon Delalande and Labex LERMIT fellowships respectively. 


\section{References}

[1] Global Atlas on cardiovascular disease prevention and control, World Health Organization (2014).

[2] C.B. Johnson, J. Sulpher, E. Stadnick, Evaluation, prevention and management of cancer therapy-induced cardiotoxicity: a contemporary approach for clinicians, Curr Opin Cardiol 30(2) (2015) 197-204.

[3] S.E. Lipshultz, T.R. Cochran, V.I. Franco, T.L. Miller, Treatment-related cardiotoxicity in survivors of childhood cancer, Nature reviews. Clinical oncology 10(12) (2013) 697-710.

[4] M. Lotrionte, G. Biondi-Zoccai, A. Abbate, G. Lanzetta, F. D'Ascenzo, V. Malavasi, M. Peruzzi, G. Frati, G. Palazzoni, Review and meta-analysis of incidence and clinical predictors of anthracycline cardiotoxicity, Am J Cardiol 112(12) (2013) 1980-4.

[5] N. Haddy, S. Diallo, C. El-Fayech, B. Schwartz, F. Pein, M. Hawkins, C. Veres, O. Oberlin, C. Guibout, H. Pacquement, M. Munzer, T.D. N'Guyen, P.Y. Bondiau, D. Berchery, A. Laprie, P.Y. Scarabin, X. Jouven, A. Bridier, S. Koscielny, E. Deutsch, I. Diallo, F. de Vathaire, Cardiac Diseases Following Childhood Cancer Treatment: Cohort Study, Circulation 133(1) (2016) 31-8.

[6] D. Cardinale, A. Colombo, G. Bacchiani, I. Tedeschi, C.A. Meroni, F. Veglia, M. Civelli, G. Lamantia, N. Colombo, G. Curigliano, C. Fiorentini, C.M. Cipolla, Early detection of anthracycline cardiotoxicity and improvement with heart failure therapy, Circulation 131(22) (2015) 1981-8.

[7] Y. Octavia, C.G. Tocchetti, K.L. Gabrielson, S. Janssens, H.J. Crijns, A.L. Moens, Doxorubicin-induced cardiomyopathy: from molecular mechanisms to therapeutic strategies, J Mol Cell Cardiol 52(6) (2012) 1213-25.

[8] J.S. Dickey, V.A. Rao, Current and proposed biomarkers of anthracycline cardiotoxicity in cancer: emerging opportunities in oxidative damage and autophagy, Current molecular medicine 12(6) (2012) 763-71.

[9] D.M. Bers, Calcium cycling and signaling in cardiac myocytes, Annu Rev Physiol 70 (2008) 23-49.

[10] J.P. Benitah, B.G. Kerfant, G. Vassort, S. Richard, A.M. Gomez, Altered communication between L-type calcium channels and ryanodine receptors in heart failure, Frontiers in Bioscience 7 (2002) E263-E275.

[11] A.M. Gómez, H.H. Valdivia, H. Cheng, M.R. Lederer, L.F. Santana, M.B. Cannell, S.A. McCune, R.A. Altschuld, W.J. Lederer, Defective excitation-contraction coupling in experimental cardiac hypertrophy and heart failure, Science 276(5313) (1997) 800-6.

[12] G.S. Gómez AM, Dilly KW, Vassort G, Lederer WJ. , Heart failure after myocardial infarction: altered excitation-contraction coupling., Circulation. 104(6) (2001) 688-693.

[13] E. Perrier, B.G. Kerfant, N. Lalevee, P. Bideaux, M.F. Rossier, S. Richard, A.M. Gómez, J.P. Benitah, Mineralocorticoid receptor antagonism prevents the electrical remodeling that precedes cellular hypertrophy after myocardial infarction., Circulation 110(7) (2004) 776-83.

[14] L. Pereira, J. Matthes, I. Schuster, H.H. Valdivia, S. Herzig, S. Richard, A.M. Gómez, Mechanisms of [Ca2+]i Transient Decrease in Cardiomyopathy of db/db Type 2 Diabetic Mice, Diabetes 55(3) (2006) 608-15. 
[15] S.E. Litwin, D. Zhang, J.H.B. Bridge, Dyssynchronous Ca2+ Sparks in Myocytes From Infarcted Hearts, Circ Res 87(11) (2000) 1040-1047.

[16] M. Mazevet, M. Moulin, A. Llach-Martinez, C. Chargari, E. Deutsch, A.M. Gomez, E. Morel, Complications of chemotherapy, a basic science update, Presse Med 42(9 Pt 2) (2013) e352-61.

[17] C.M. Sag, A.C. Kohler, M.E. Anderson, J. Backs, L.S. Maier, CaMKII-dependent SR Ca leak contributes to doxorubicin-induced impaired $\mathrm{Ca}$ handling in isolated cardiac myocytes, J Mol Cell Cardiol 51(5) (2011) 749-59.

[18] H. Cheng, W.J. Lederer, M.B. Cannell, Calcium sparks: elementary events underlying excitation-contraction coupling in heart muscle, Science 262(5134) (1993) 740-4.

[19] K. Saeki, I. Obi, N. Ogiku, M. Shigekawa, T. Imagawa, T. Matsumoto, Doxorubicin directly binds to the cardiac-type ryanodine receptor, Life sciences 70(20) (2002) 237789.

[20] A.D. Hanna, A. Lam, C. Thekkedam, H. Willemse, A.F. Dulhunty, N.A. Beard, The Anthracycline Metabolite Doxorubicinol Abolishes RyR2 Sensitivity to Physiological Changes in Luminal $\mathrm{Ca}(2+)$ through an Interaction with Calsequestrin, Molecular pharmacology 92(5) (2017) 576-587.

[21] A.D. Hanna, M. Janczura, E. Cho, A.F. Dulhunty, N.A. Beard, Multiple actions of the anthracycline daunorubicin on cardiac ryanodine receptors, Molecular pharmacology 80(3) (2011) 538-49.

[22] A.D. Hanna, A. Lam, S. Tham, A.F. Dulhunty, N.A. Beard, Adverse effects of doxorubicin and its metabolic product on cardiac RyR2 and SERCA2A, Molecular pharmacology 86(4) (2014) 438-49.

[23] M. Volkova, R. Russell, 3rd, Anthracycline cardiotoxicity: prevalence, pathogenesis and treatment, Current cardiology reviews 7(4) (2011) 214-20.

[24] Y.Y. Wang, P. Mesirca, E. Marques-Sule, A. Zahradnikova, Jr., O. Villejoubert, P. D'Ocon, C. Ruiz, D. Domingo, E. Zorio, M.E. Mangoni, J.P. Benitah, A.M. Gomez, RyR2R420Q catecholaminergic polymorphic ventricular tachycardia mutation induces bradycardia by disturbing the coupled clock pacemaker mechanism, JCI Insight 2(8) (2017).

[25] M. Fernandez-Velasco, A. Rueda, N. Rizzi, J.P. Benitah, B. Colombi, C. Napolitano, S.G. Priori, S. Richard, A.M. Gomez, Increased Ca2+ Sensitivity of the Ryanodine Receptor Mutant RyR2R4496C Underlies Catecholaminergic Polymorphic Ventricular Tachycardia, Circ Res 104 (2009) 201-209.

[26] V. Monceau, A. Llach, D. Azria, A. Bridier, B. Petit, M. Mazevet, C. Strup-Perrot, T.H. To, L. Calmels, M.M. Germaini, S. Gourgou, P. Fenoglietto, C. Bourgier, A.M. Gomez, B. Escoubet, W. Dorr, J. Haagen, E. Deutsch, E. Morel, M.C. Vozenin, Epac contributes to cardiac hypertrophy and amyloidosis induced by radiotherapy but not fibrosis, Radiotherapy and oncology : journal of the European Society for Therapeutic Radiology and Oncology 111(1) (2014) 63-71.

[27] D.M. Bers, Excitation-contraction coupling and cardiac contractile force, Kluwer Academic Publishers (2001).

[28] C.M. Sag, D.P. Wadsack, S. Khabbazzadeh, M. Abesser, C. Grefe, K. Neumann, M.K. Opiela, J. Backs, E.N. Olson, J.H. Brown, S. Neef, S.K. Maier, L.S. Maier, 
Calcium/calmodulin-dependent protein kinase II contributes to cardiac arrhythmogenesis in heart failure, Circulation. Heart failure 2(6) (2009) 664-75.

[29] M. Li, V. Sala, M.C. De Santis, J. Cimino, P. Cappello, N. Pianca, A. Di Bona, J.P. Margaria, M. Martini, E. Lazzarini, F. Pirozzi, L. Rossi, I. Franco, J. Bornbaum, J. Heger, S. Rohrbach, A. Perino, C.G. Tocchetti, B.H.F. Lima, M.M. Teixeira, P.E. Porporato, R. Schulz, A. Angelini, M. Sandri, P. Ameri, S. Sciarretta, R.C.P. Lima-Junior, M. Mongillo, T. Zaglia, F. Morello, F. Novelli, E. Hirsch, A. Ghigo, Phosphoinositide 3Kinase Gamma Inhibition Protects from Anthracycline Cardiotoxicity and Reduces Tumor Growth, Circulation (2018).

[30] A.E. Bottone, E.L. de Beer, E.E. Voest, Anthracyclines enhance tension development in cardiac muscle by direct interaction with the contractile system, $\mathrm{J}$ Mol Cell Cardiol 29(3) (1997) 1001-8.

[31] T. Takaseya, M. Ishimatsu, E. Tayama, A. Nishi, T. Akasu, S. Aoyagi, Mechanical unloading improves intracellular $\mathrm{Ca} 2+$ regulation in rats with doxorubicin-induced cardiomyopathy, J Am Coll Cardiol 44(11) (2004) 2239-46.

[32] Y. Zhang, Y. Chen, M. Zhang, Y. Tang, Y. Xie, X. Huang, Y. Li, Doxorubicin induces sarcoplasmic reticulum calcium regulation dysfunction via the decrease of SERCA2 and phospholamban expressions in rats, Cell biochemistry and biophysics $70(3)$ (2014) 1791-8.

[33] R.D. Olson, H.A. Gambliel, R.E. Vestal, S.E. Shadle, H.A. Charlier, Jr., B.J. Cusack, Doxorubicin cardiac dysfunction: effects on calcium regulatory proteins, sarcoplasmic reticulum, and triiodothyronine, Cardiovascular toxicology 5(3) (2005) 26983.

[34] B.E. Burke, R.D. Olson, B.J. Cusack, H.A. Gambliel, W.H. Dillmann, Anthracycline cardiotoxicity in transgenic mice overexpressing SR Ca2+-ATPase, Biochem Biophys Res Commun 303(2) (2003) 504-7.

[35] D.A. Dodd, J.B. Atkinson, R.D. Olson, S. Buck, B.J. Cusack, S. Fleischer, R.J. Boucek, Jr., Doxorubicin cardiomyopathy is associated with a decrease in calcium release channel of the sarcoplasmic reticulum in a chronic rabbit model, J Clin Invest 91(4) (1993) 1697-705.

[36] P.B. Johansen, Doxorubicin pharmacokinetics after intravenous and intraperitoneal administration in the nude mouse, Cancer Chemother Pharmacol 5(4) (1981) 267-70.

[37] J.R. Erickson, M.L. Joiner, X. Guan, W. Kutschke, J. Yang, C.V. Oddis, R.K. Bartlett, J.S. Lowe, S.E. O'Donnell, N. Aykin-Burns, M.C. Zimmerman, K. Zimmerman, A.J. Ham, R.M. Weiss, D.R. Spitz, M.A. Shea, R.J. Colbran, P.J. Mohler, M.E. Anderson, A dynamic pathway for calcium-independent activation of CaMKII by methionine oxidation, Cell 133(3) (2008) 462-74.

[38] J.P. Brennan, S.C. Bardswell, J.R. Burgoyne, W. Fuller, E. Schroder, R. Wait, S. Begum, J.C. Kentish, P. Eaton, Oxidant-induced activation of type I protein kinase A is mediated by RI subunit interprotein disulfide bond formation, J Biol Chem 281(31) (2006) 21827-36.

[39] J. Duan, J. Tao, M. Zhai, C. Li, N. Zhou, J. Lv, L. Wang, L. Lin, R. Bai, Anticancer drugs-related QTc prolongation, torsade de pointes and sudden death: current evidence and future research perspectives, Oncotarget 9(39) (2018) 25738-25749. 


\section{Figure legends}

Figure 1: Doxorubicin induces a cardiotoxicity in mice at 15 weeks after the last injection.

Representative $\mathrm{M}$ mode echocardiograms of mice from saline and doxorubicin treatment groups (A). Ejection fraction (B), fractional release (C) and end diastolic diameter (D) of treated mice at 2, 6 and 15 weeks after the last injection. The number of treated mice are indicated in the column of the B graph. E. Representative left ventricular cardiac tissue sections after Picrosirius red illustrating the interstitial collagen 15 weeks after the last saline (left) or Dox (right) injection, and the corresponding fibrosis quantification ( $N=4$ each group). ${ }^{*} p<0.05$ compared with control.

Figure 2. Evolution of $\left[\mathrm{Ca}^{2+}\right]_{i}$ transients after chronic Dox treatment. A. Representative line scan confocal microscopy images taken from cardiomyocytes at 2 (left), 6 (middle) and 15 weeks after last saline (top) or Dox (bottom) injection during electrical field stimulation at $2 \mathrm{~Hz}$. B. Peak $\left[\mathrm{Ca}^{2+}\right]_{i}$ transient in ventricular cardiomyocytes in saline treated (gray bars, Saline) or Dox treated (blue bars, Dox) at 2, 6 and 15 weeks $(2 w, 6 w, 15 w)$ after the last injection, normalized to saline treated mice. Number of cells is noted in the bars. C. Normalized decay time constant of the $\left[\mathrm{Ca}^{2+}\right]_{\mathrm{i}}$ transients (obtained by fitting the decaying phase to a single exponential). Colors and symbols as in B. C. Unloaded cell shortening in cardiomyocytes from each group. * $p<0.05$.

Figure 3. Action potential duration is unaffected by Dox treatment. Averaged values of action potential duration at 20 (APD20\%), 50 (APD 50\%) and 90 (APD90\%) \% of repolarization in saline (gray bars) and Dox treated mice (blue bars) at 2 weeks (A), 6 weeks (B) and 15 weeks (C) after the last injection. Labeling as in Fig. 2. Inset representative AP traces recorded in saline (black line) or Dox (gray line) treated mice.

Figure 4. SR Ca ${ }^{2+}$ load is depressed 15 weeks after the last Dox injection. A. Representative line scan images of a cardiac myocyte treated with saline (top) or Dox (bottom) at 2 (left), 6 (middle) and 15 (right) weeks after the last injection during field stimulation and subsequent caffeine $(10 \mathrm{mM})$ rapid application. B. Normalized averaged values of peak caffeine evoked $\left[\mathrm{Ca}^{2+}\right]_{i}$ transients at different times after the last injection. 
Number of cells is noted in the bars. C. Normalized averaged decay time constant of the caffeine-evoked $\left[\mathrm{Ca}^{2+}\right]_{i}$ transient obtained by fitting the decay phase to a single exponential. D. Immunoblots of NCX (left) and normalized level expression of NCX protein (right) at 2, 6, and 15 weeks after the last injection. Colors and symbols as in Fig. 2. * $p<0.05$ Dox vs. Saline.

Figure 5. Time-dependent modulation of Calcium handling proteins induced by Doxorubicin at 2, 6 and 15 weeks after the last injection in vivo Immunoblots showing SERCA (A) and its quantification (B) in each group studied. C Examples of immunoblots of total and phosphorylated phospholamban. Quantitative protein expression of total (D), P-S16- (E) and P-T17 phospholamban (F) from the left ventricle of mice injected or not (saline) with Dox at 2, 6 or 15 weeks after the last treatment. Numbers of mice are indicated as above. Immunoblots were quantified and normalized to $\beta$-actin expression and internal control. Data are mean \pm SEM and are expressed as percentage of the control value (saline-injected mice). ${ }^{*} p<0.05,{ }^{* *} p<0.01,{ }^{* * *} p<0.001$ compared to saline.

Fig. 6. Spontaneous $\mathrm{Ca}^{2+}$ release in enhanced early and late after Dox treatment. A. Representative line-scan images showing individual $\mathrm{Ca}^{2+}$ sparks in cardiac cells isolated 2 (left), 6 (middle) or 15 (right) weeks after the last saline (top) or Dox (bottom) injection. B. Normalized $\mathrm{Ca}^{2+}$ sparks frequency in each experimental group. Number of cells is noted in each bar.

C. Immunoblots against total or phosphorylated RyR2 and $\beta$-actin expression from cardiac myocytes isolated from mice hearts at 2, 6 and 15 weeks after the last saline or Dox injection. Quantification of total RyR2 (D), P-S2808-RyR2 (E) and P-S2814-RyR2 (F) at different times after the last injection. G. $\mathrm{Ca}^{2+}$ wave frequency in each cell group. Insert a line scan confocal image showing a $\mathrm{Ca}^{2+}$ wave. $\mathbf{H}$. ECG recorded in a mouse 2 weeks after the last Dox injection showing ventricular ectopy (VE). Color and symbols as in Fig. 2.

Supp. Fig. 1. Morphometric characteristics of mice at different times after the last Dox injection. 
A. Body weight of mice treated with doxorubicin or vehicle (Saline solution $\mathrm{NaCl} 0.9 \%$ ).

B: Ratio of heart weight/tibia length of treated mice at 2, 6 and 15 weeks after the last injection. The number of treated mice are indicated in the column of the graph. Results are expressed as percentage of control mice values. No significant difference of the ratio heart weight/tibia length between control and doxorubicin-treated mice after 2, 6 or 15 weeks have been observed. C. Hematoxylin/eosin stain of mice left ventricular section at 2 (left), 6 (middle) or 15 (right) weeks after the last saline (top) or Dox (bottom) injection. No significant structural alterations or inflammation have been detected.

Supp. Fig. S2. $\mathrm{Ca}^{2+}$ sparks characteristics in cardiomcyocytes isolated from mice 2, 6 or 15 weeks after the last Dox or saline injection. A. $\mathrm{Ca}^{2+}$ spark amplitude, expressed in peak F/FO where $\mathrm{F}$ is the fluorescence and F0 the diastolic fluorescence. $\mathrm{B}$ Duration at half the maximum, and $\mathrm{C}$ Width at half maximum. $\mathrm{N}$ here indicates the $\mathrm{Ca}^{2+}$ sparks number. ${ }^{* *} p<0.01,{ }^{* * *} p<0.001$ compared to saline. 
A

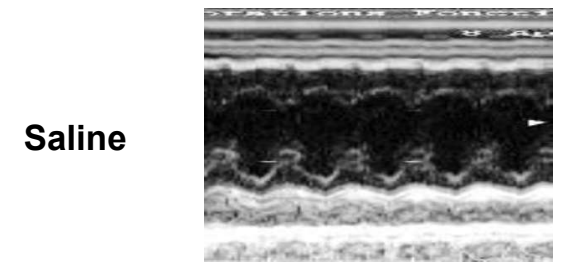

Dox
$0.5 \mathrm{~cm}$

B

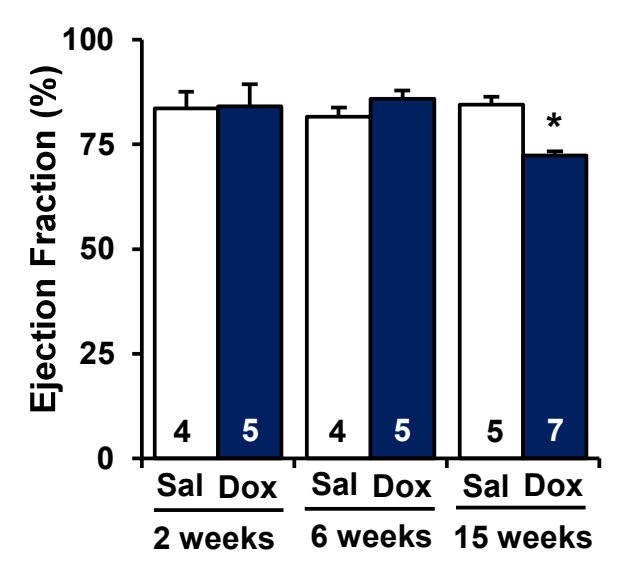

E
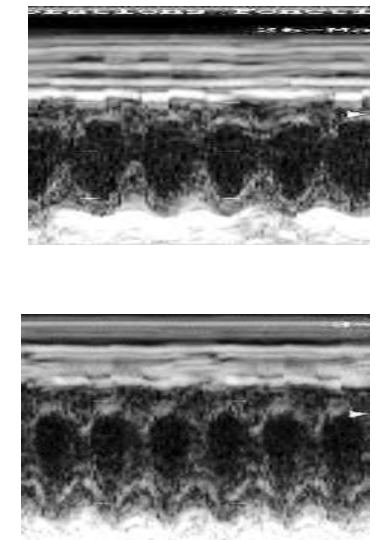

$\overline{250 \mathrm{~ms}}$
6 weeks

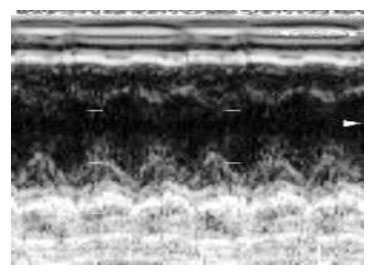

C

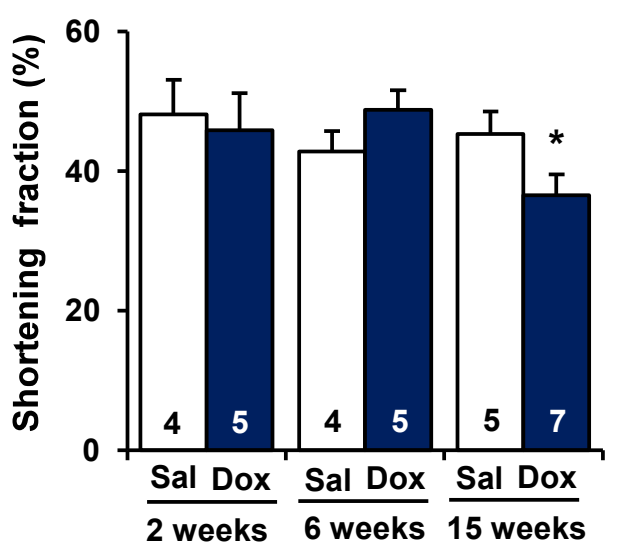

15 weeks
Saline

Dox

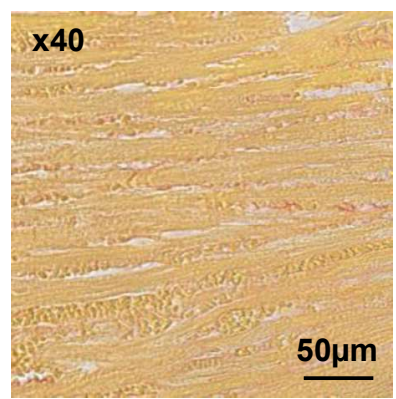

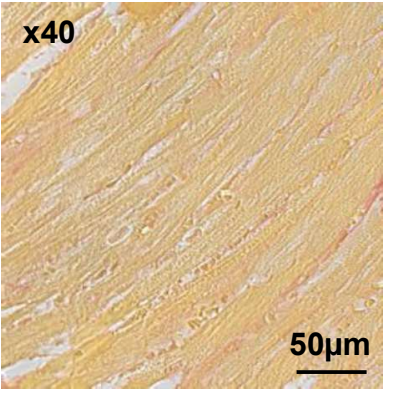

15 weeks
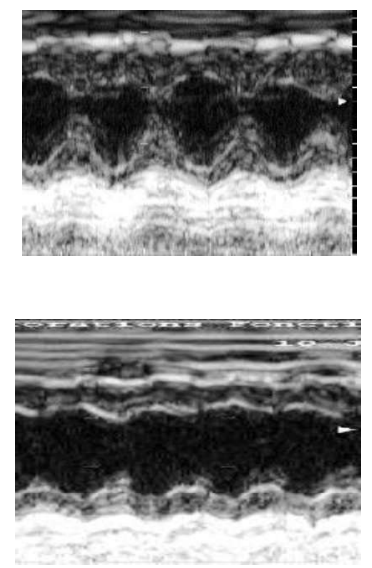

D
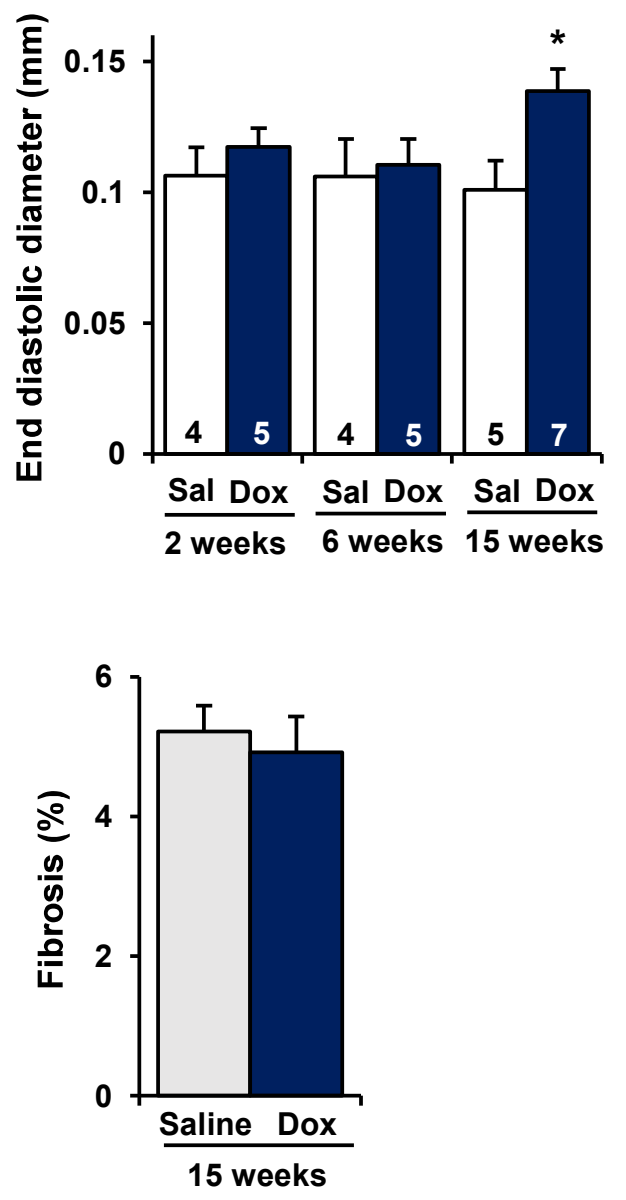
A

$50 \mu \mathrm{m}$
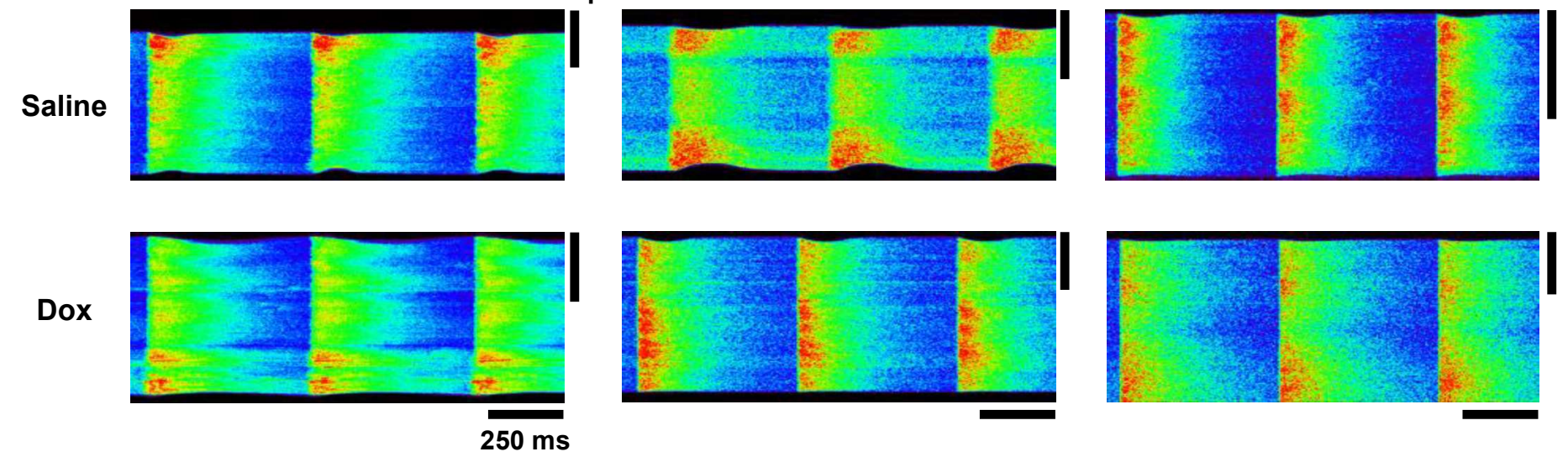

B

C

D
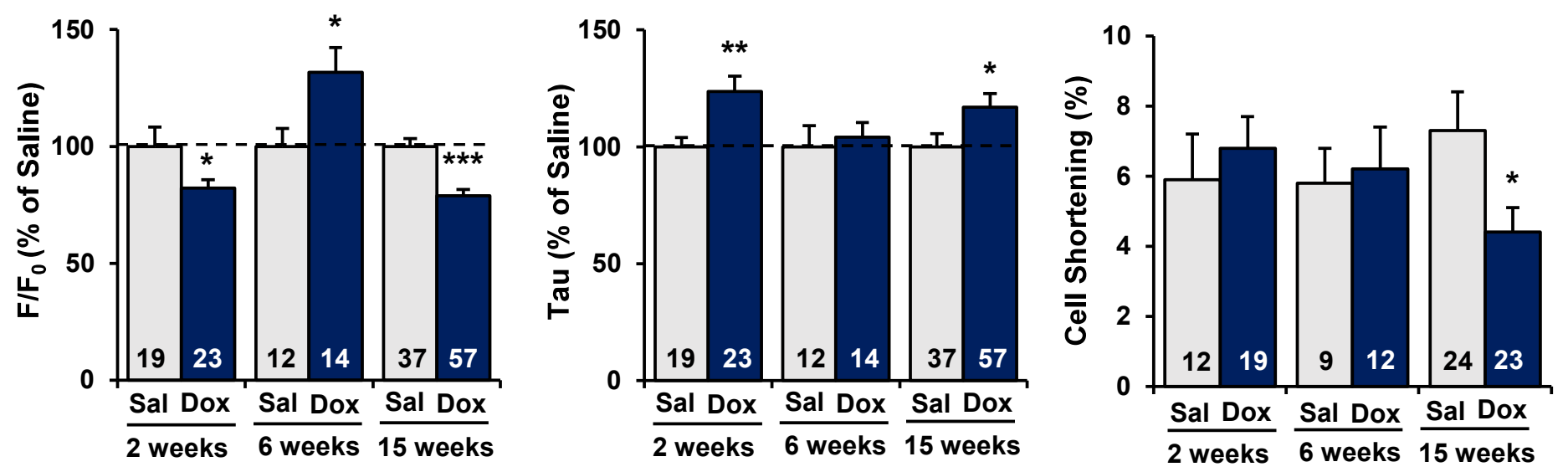
A

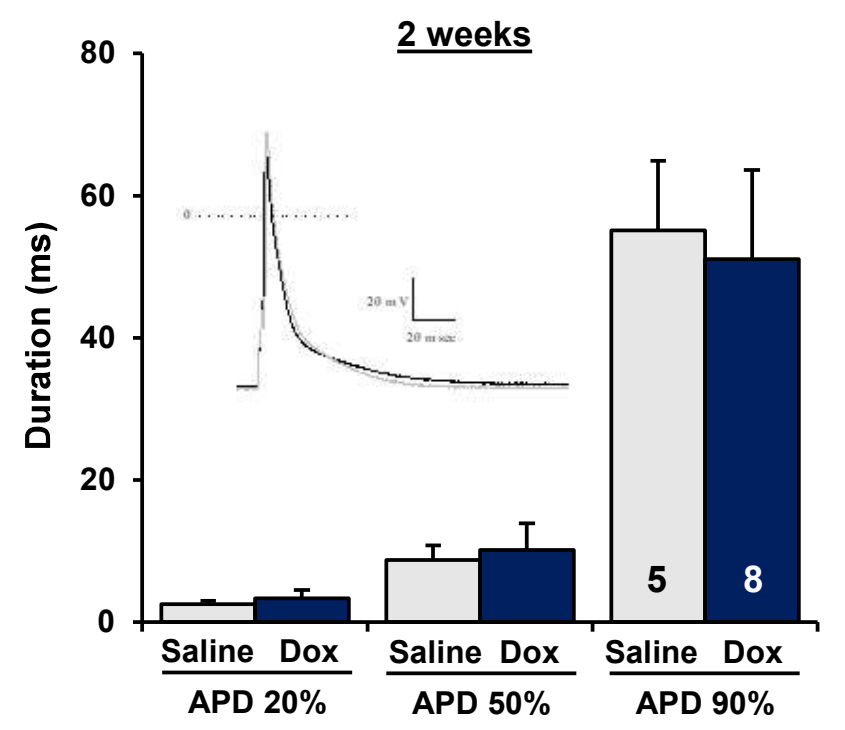

B

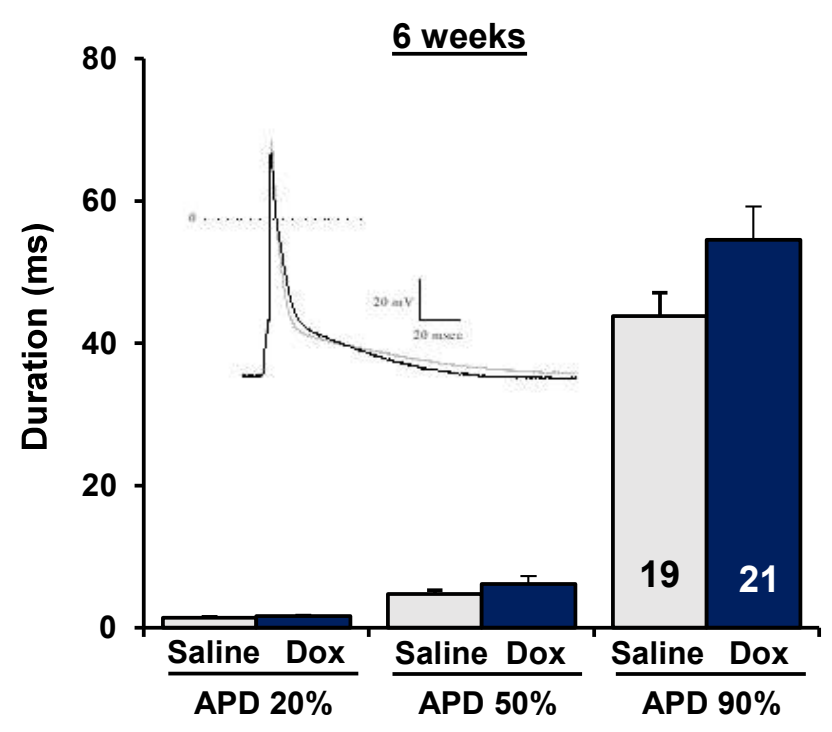

C

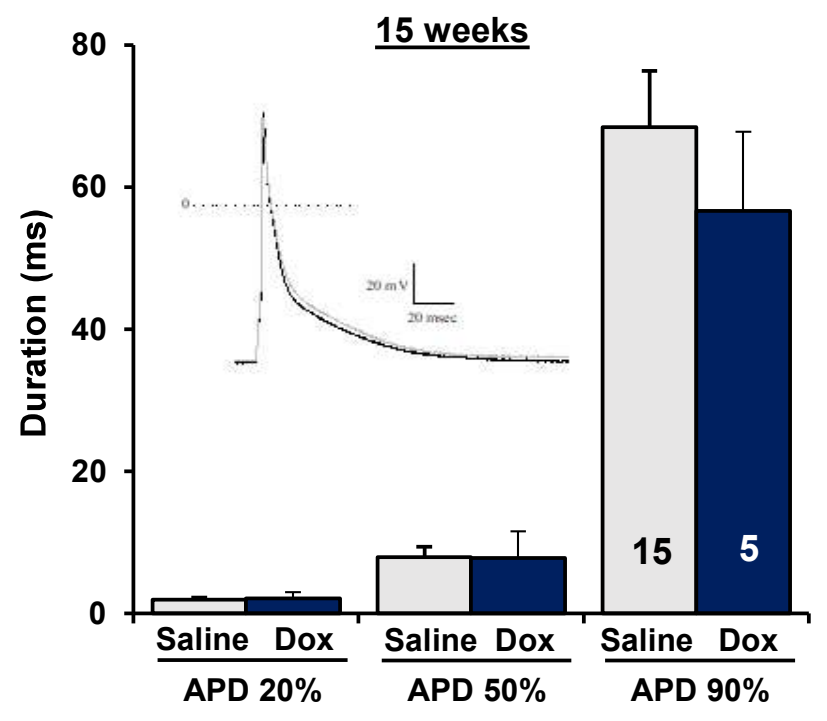


A
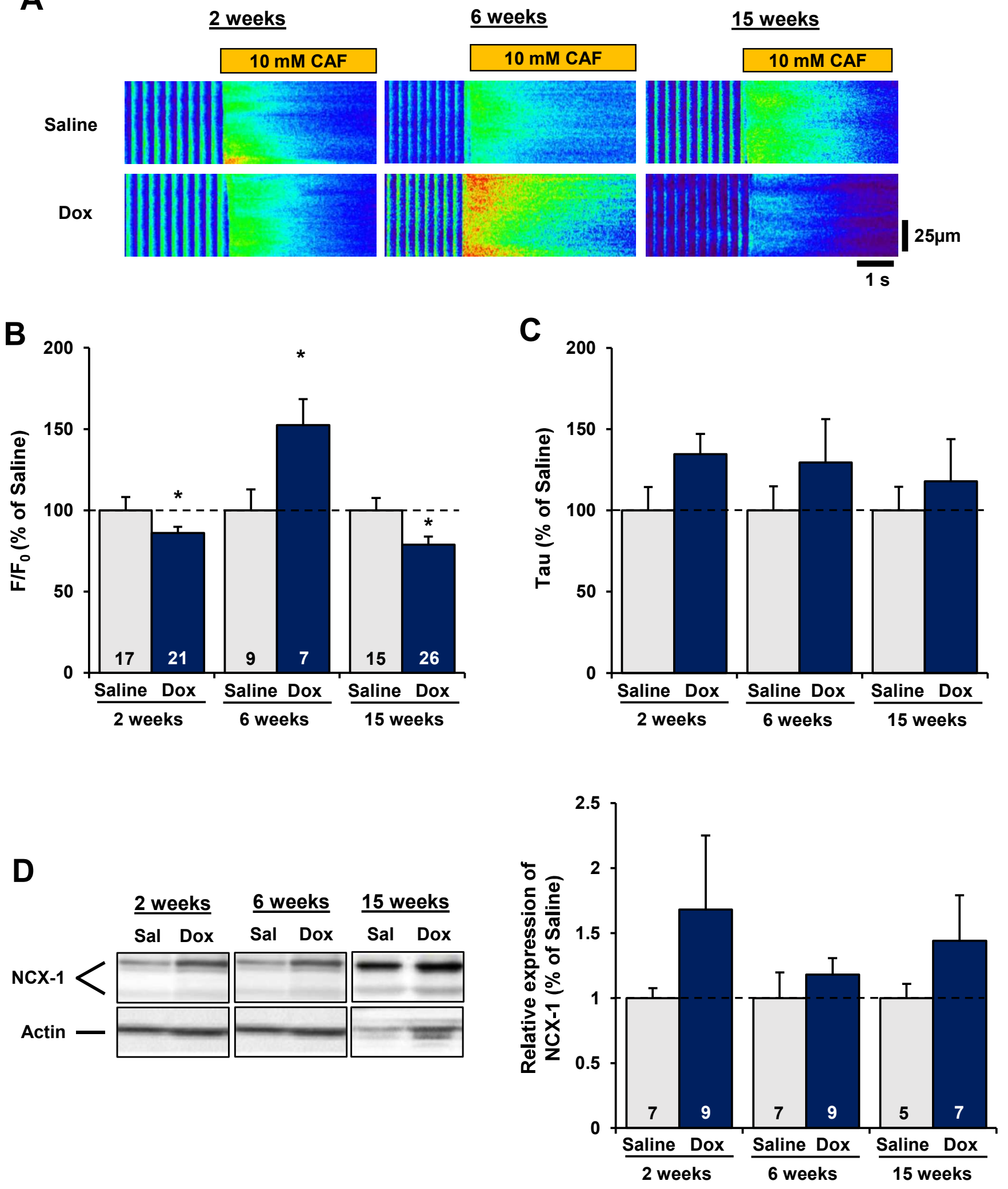


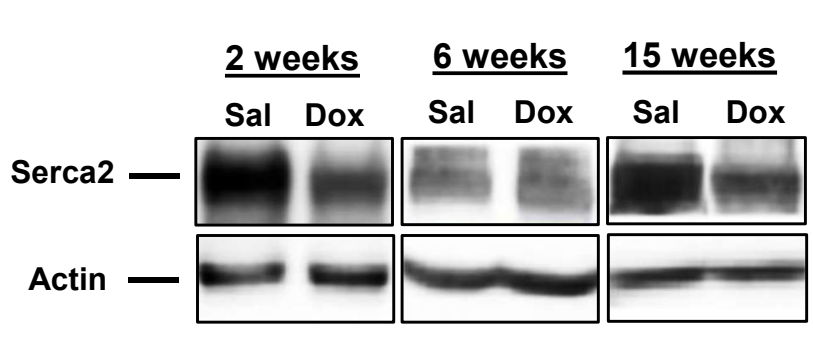

C

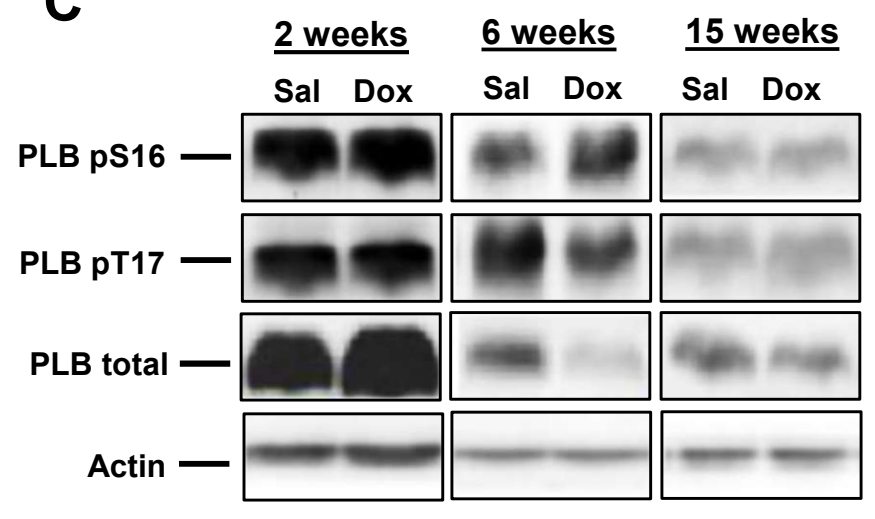

E

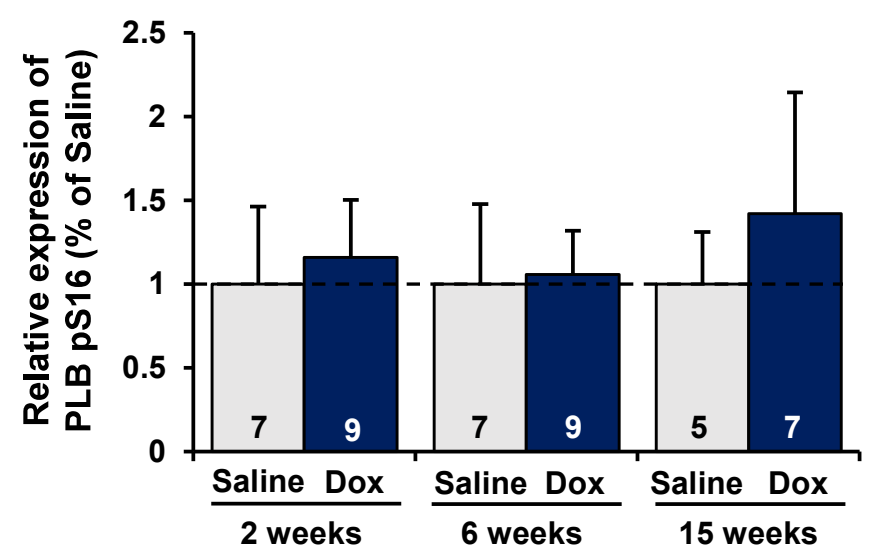

B

1.5

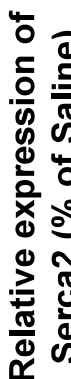

0.5

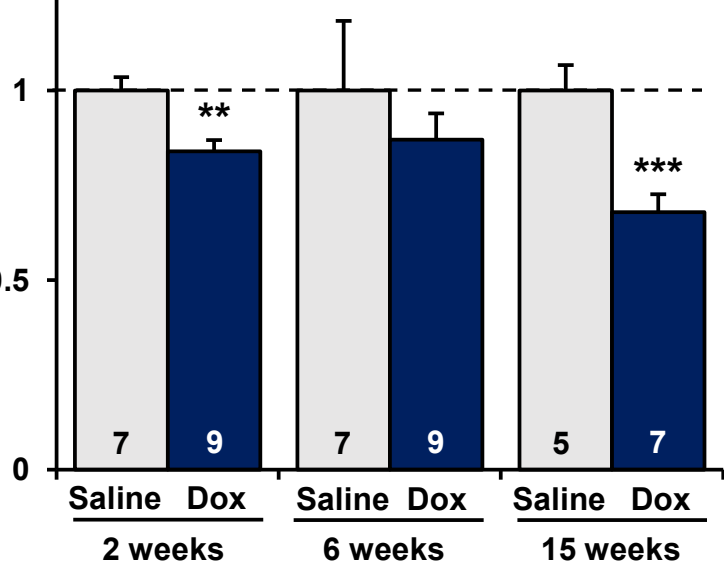

D

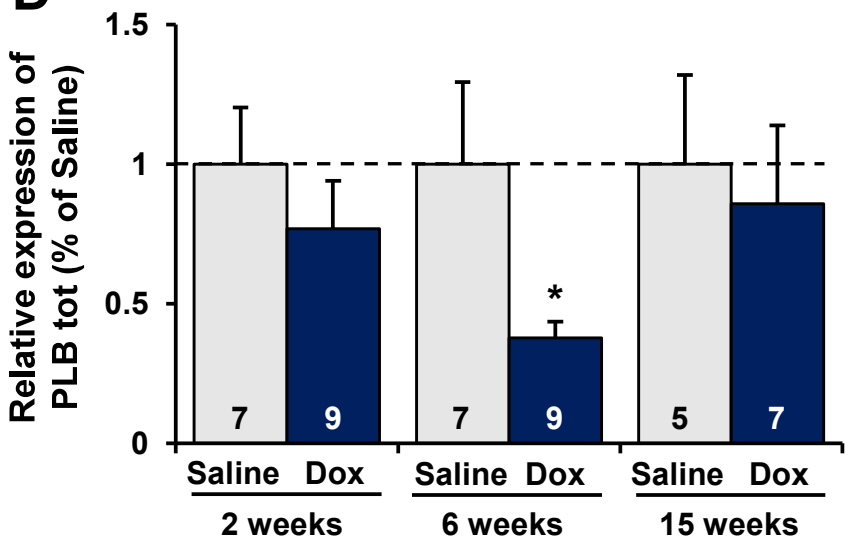

F

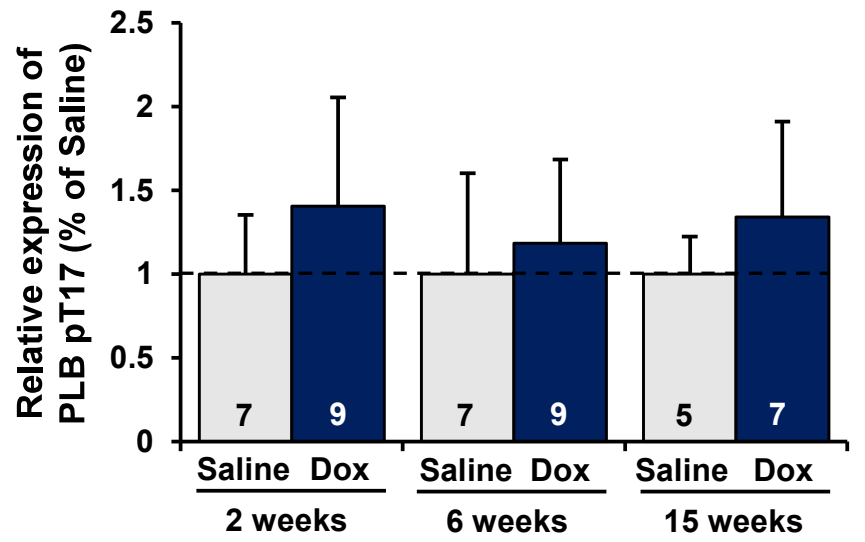



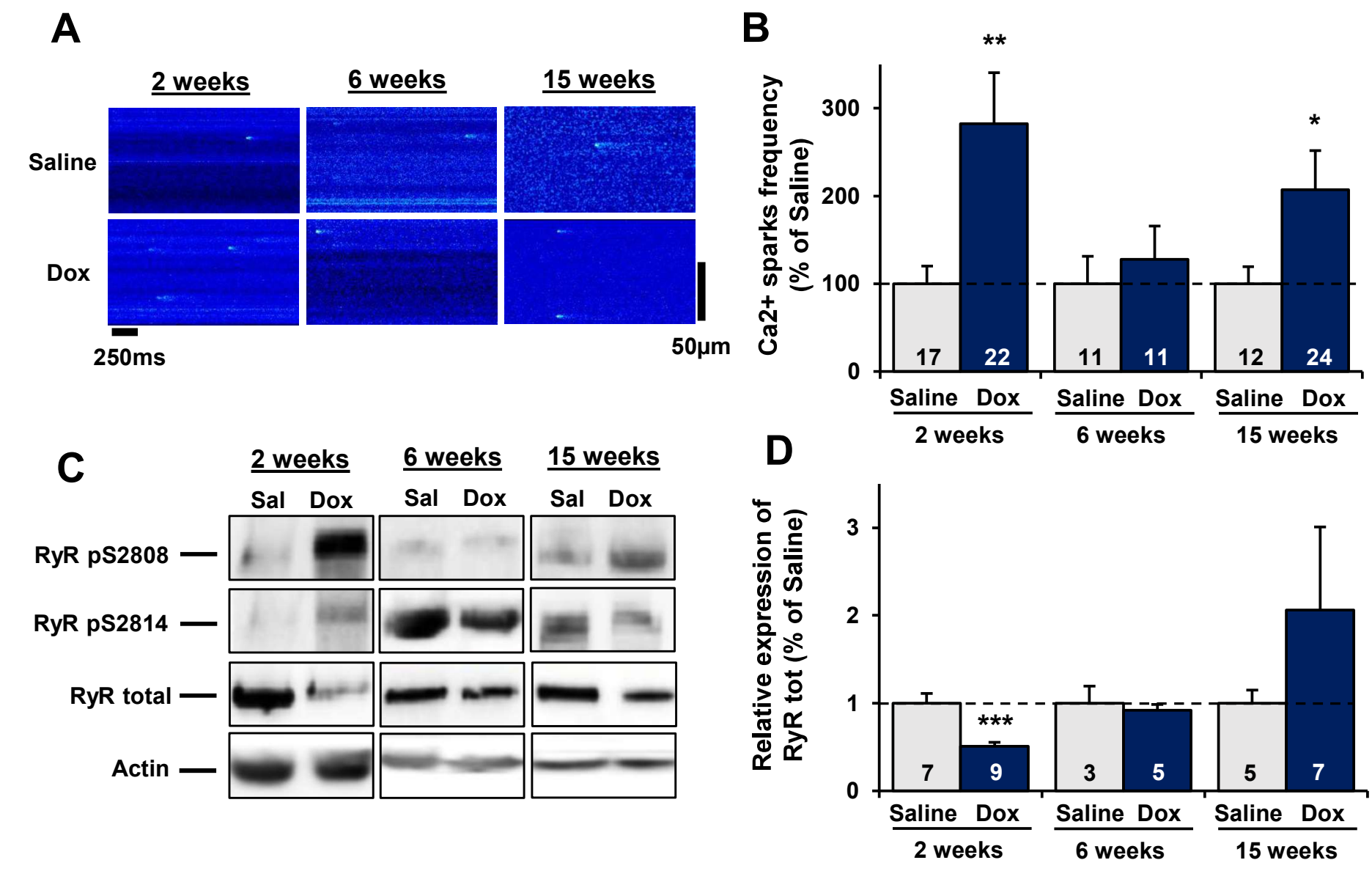

E
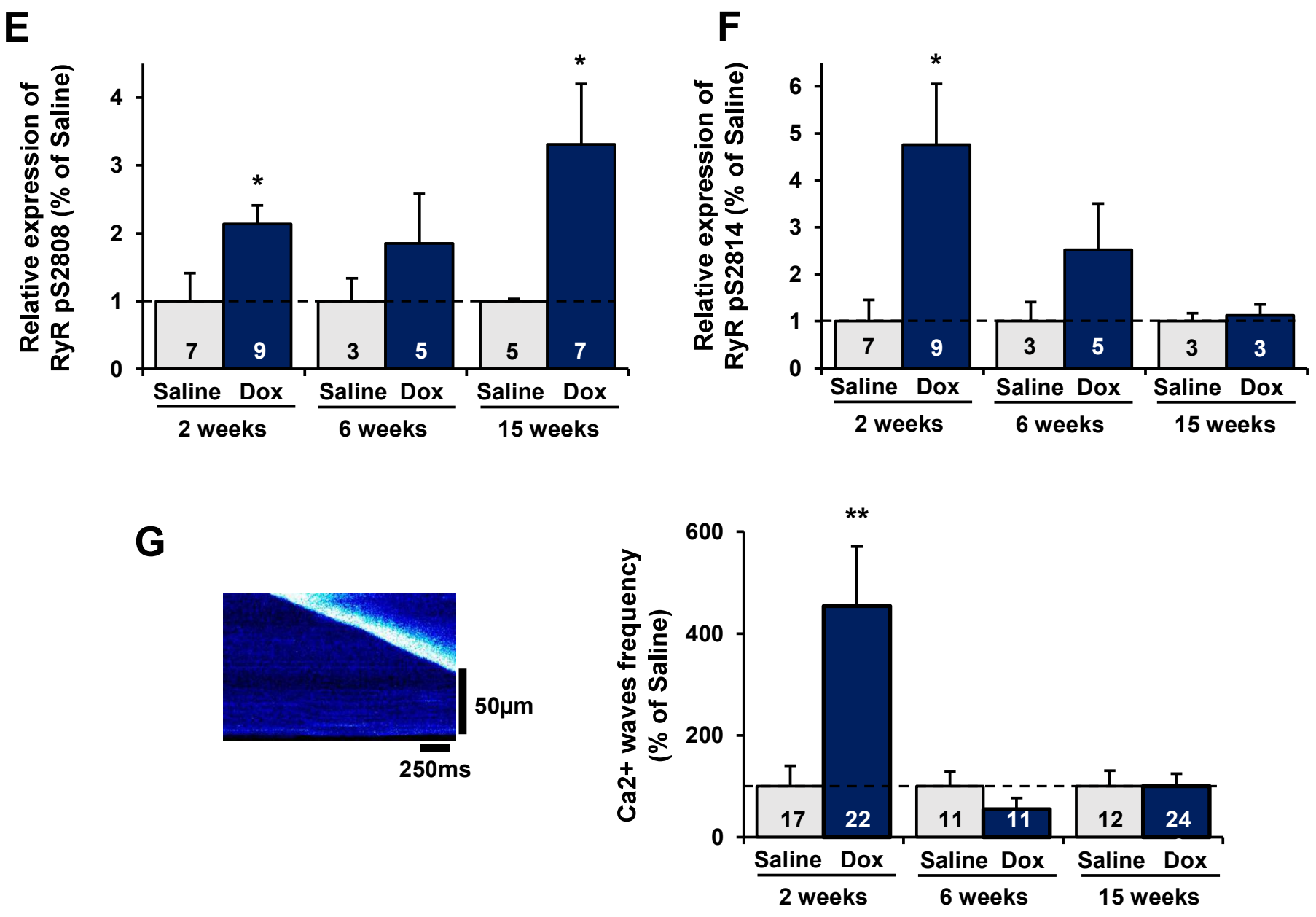
A
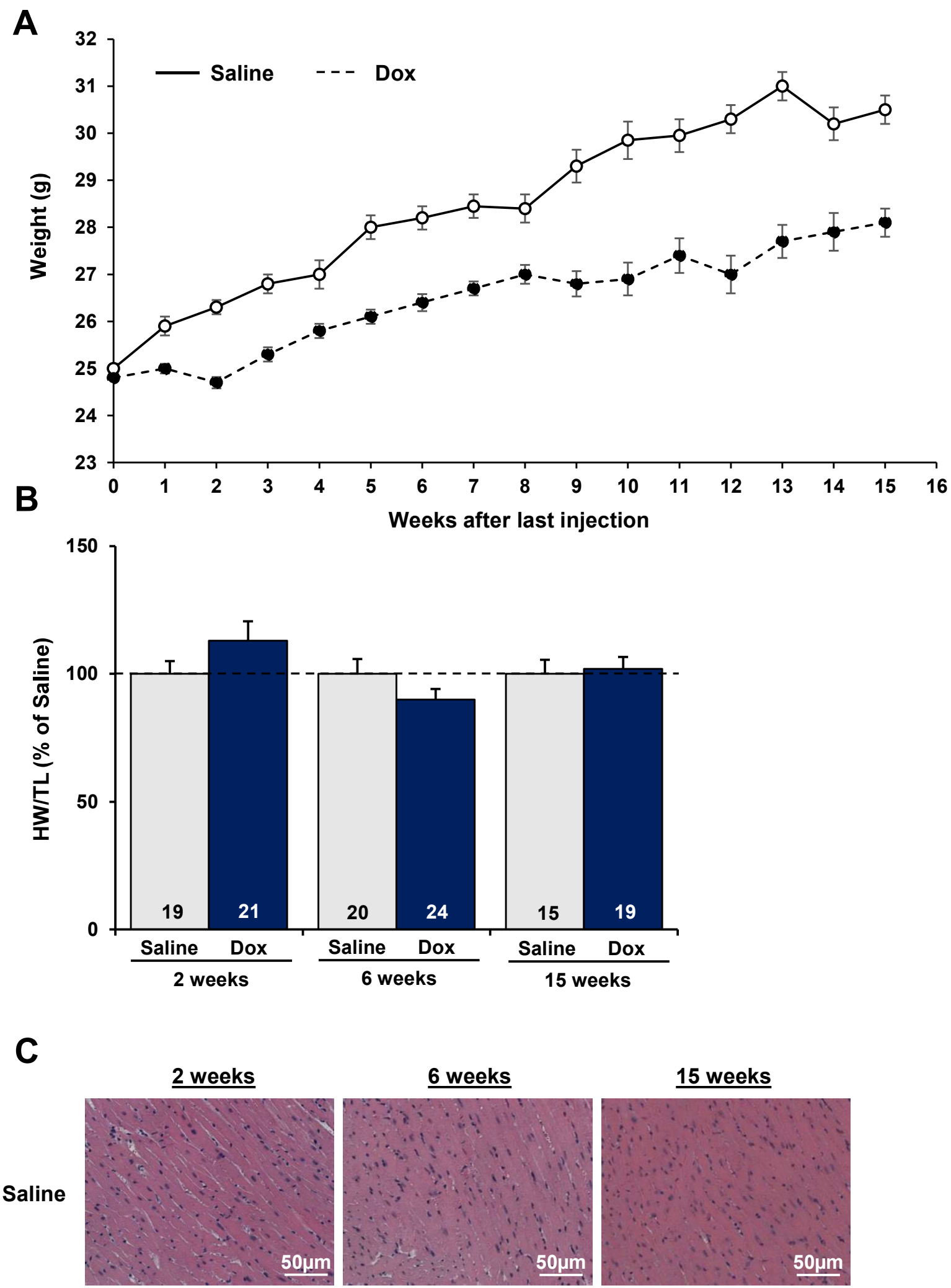

15 weeks
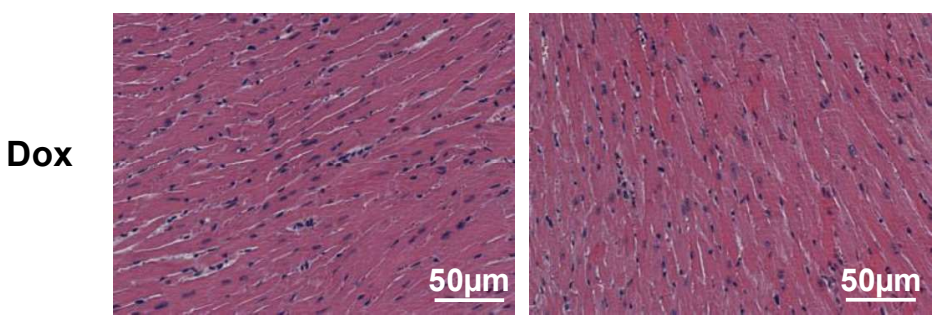

50 um

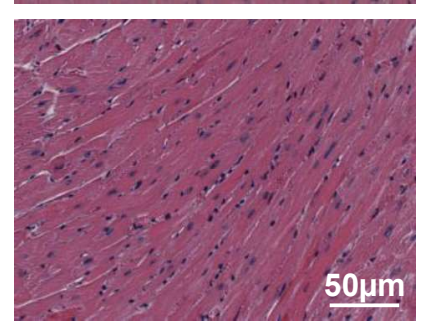




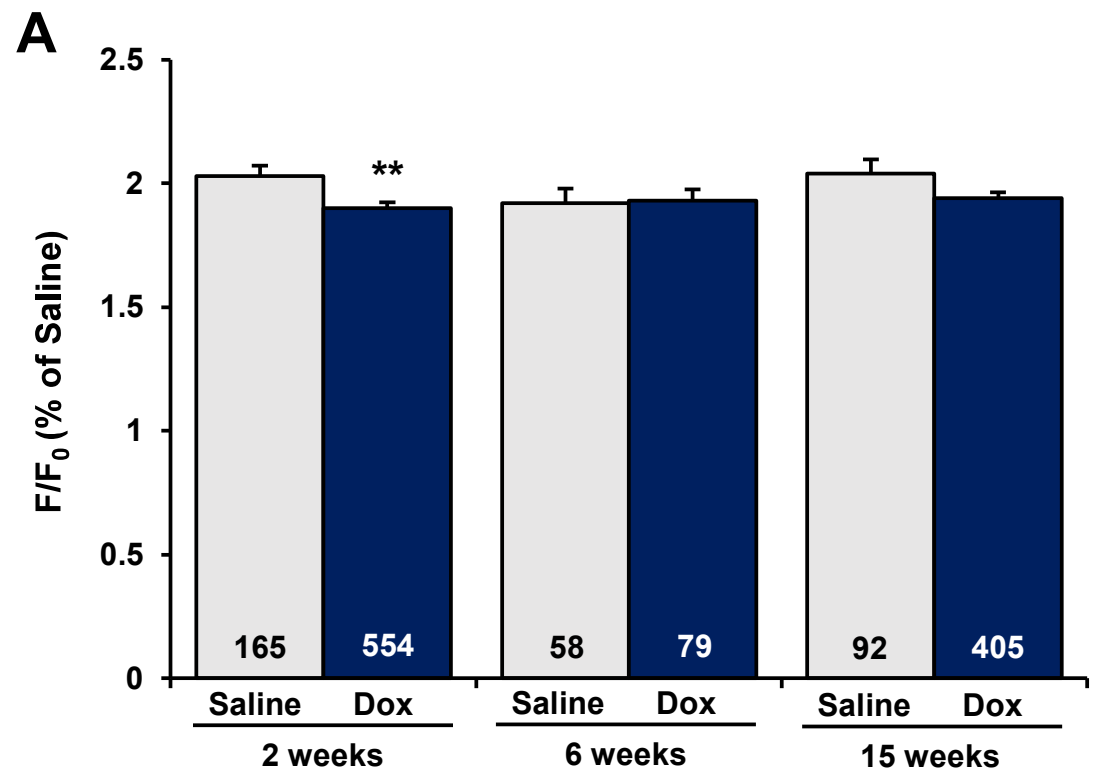

B

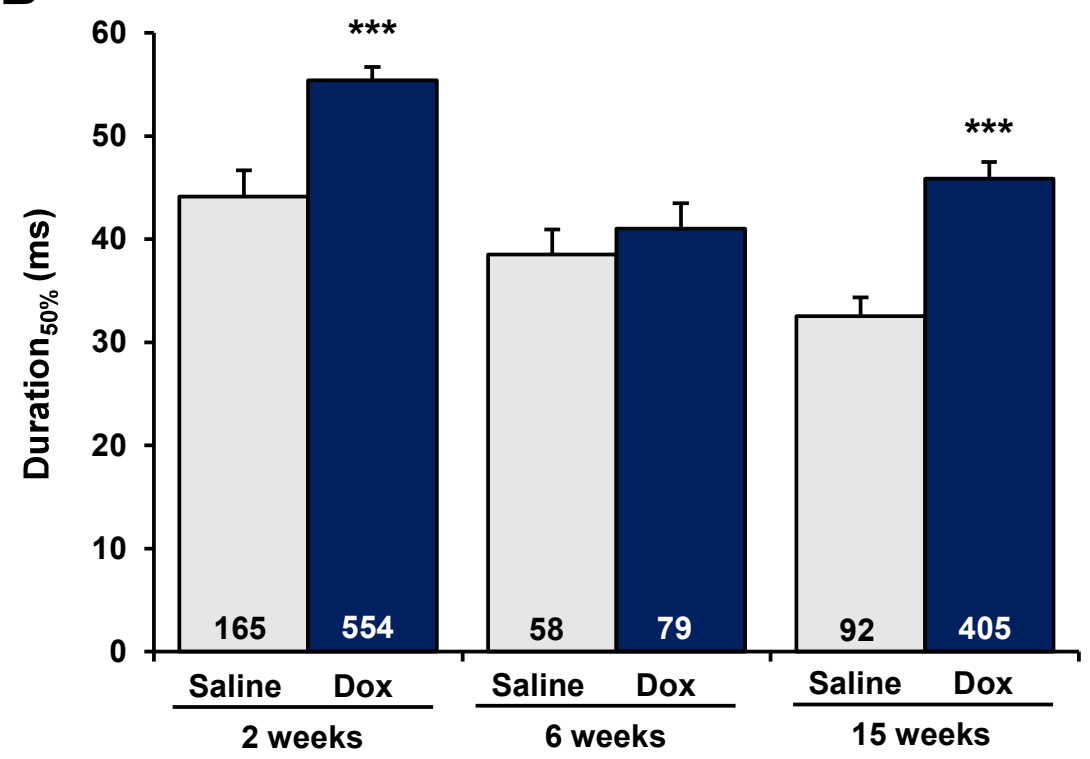

C

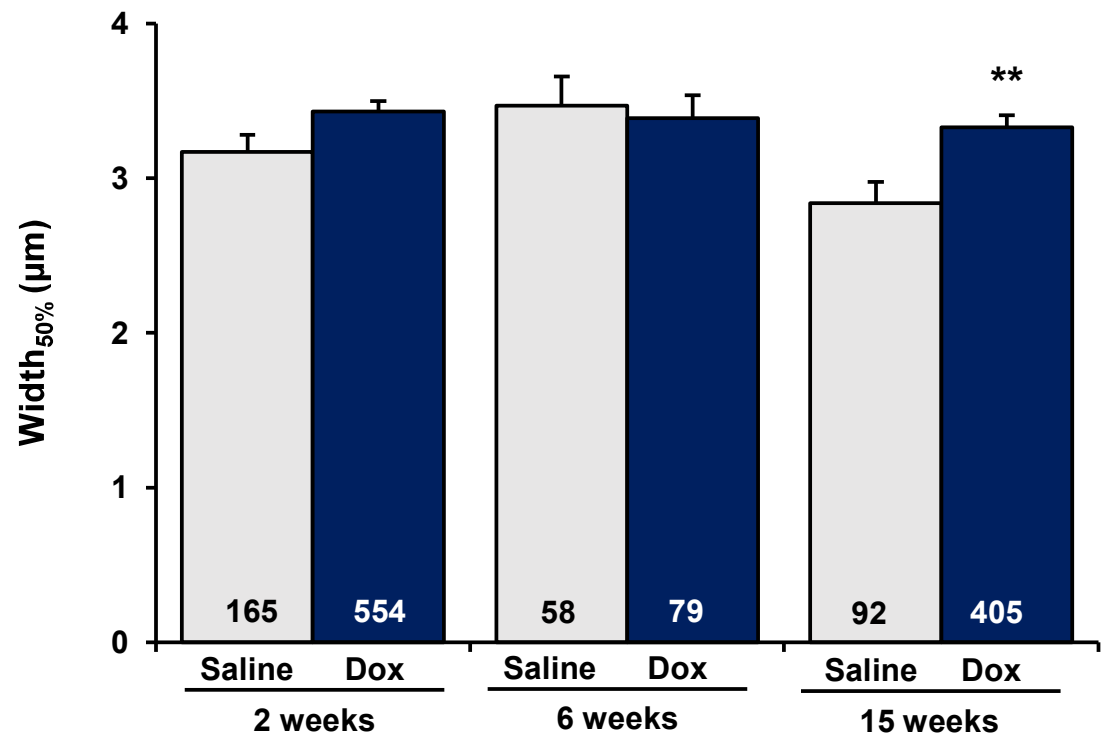

